\title{
Cognitive deficits and decreased locomotor activity induced by single-walled carbon nanotubes and neuroprotective effects of ascorbic acid
}

\author{
This article was published in the following Dove Press journal: \\ International Journal of Nanomedicine \\ II February 2014 \\ Number of times this article has been viewed
}

\author{
Xudong Liu',* \\ Yuchao Zhang ${ }^{1, *}$ \\ Jinquan $\mathrm{Li}^{\prime}$ \\ Dong Wang' \\ Yang $\mathrm{Wu}^{\prime}$ \\ Yan $\mathrm{Li}^{2}$ \\ Zhisong $\mathrm{Lu}^{3}$ \\ Samuel CT Yu ${ }^{4}$ \\ Rui $\mathrm{Li}^{\prime}$ \\ Xu Yang'
}

'Laboratory of Environmental Biomedicine, Hubei Key Laboratory of Genetic

Regulation and Integrative Biology, College

of Life Science, Central China Normal

University, Wuhan, People's Republic

of China; ${ }^{2} \mathrm{Chemical}$ and Biomolecular

Engineering Department, Hong Kong

University of Science and Technology,

Hong Kong Special Administrative Region;

${ }^{3}$ Institute for Clean Energy and Advanced

Materials, Southwest University, Chongging,

People's Republic of China; ${ }^{4}$ Division of

Environment, Hong Kong University of

Science and Technology, Hong Kong Special

Administrative Region

*These authors contributed equally to this work

Correspondence: $\mathrm{Xu}$ Yang

Hubei Key Laboratory of Genetic Regulation

and Integrative Biology, College of Life Science,

Central China Normal University, Wuhan 430079,

People's Republic of China

Tel +86 13871361954

Fax +86 2767861936

Email yangxu@mail.ccnu.edu.cn

Rui Li

Hubei Key Laboratory of Genetic Regulation and Integrative Biology, College of Life Science, Central China Normal University, Wuhan 430079, People's Republic of China

Tel +86 I5। 72385189

Fax +862767861936

Email ruili@mail.ccnu.edu.cn
Abstract: Single-walled carbon nanotubes (SWCNTs) have shown increasing promise in the field of biomedicine, especially in applications related to the nervous system. However, there are limited studies available on the neurotoxicity of SWCNTs used in vivo. In this study, neurobehavioral changes caused by SWCNTs in mice and oxidative stress were investigated. The results of ethological analysis (Morris water maze and open-field test), brain histopathological examination, and assessments of oxidative stress (reactive oxygen species [ROS], malondialdehyde [MDA], and glutathione [GSH]), inflammation (nuclear factor $\kappa \mathrm{B}$, tumor necrosis factor $\alpha$, interleukin-1 $\beta$ ), and apoptosis (cysteine-aspartic acid protease 3 ) in brains showed that 6.25 and $12.50 \mathrm{mg} / \mathrm{kg} /$ day SWCNTs in mice could induce cognitive deficits and decreased locomotor activity, brain histopathological alterations, and increased levels of oxidative stress, inflammation, and apoptosis in mouse brains; however, $3.125 \mathrm{mg} / \mathrm{kg} /$ day SWCNTs had zero or minor adverse effects in mice, and these effects were blocked by concurrent administration of ascorbic acid. Down-regulation of oxidative stress, inflammation, and apoptosis were proposed to explain the neuroprotective effects of ascorbic acid. This work suggests SWCNTs could induce cognitive deficits and decreased locomotor activity, and provides a strategy to avoid the adverse effects.

Keywords: behavioral changes, oxidative stress, inflammation, apoptosis

\section{Introduction}

Since their emergence a few decades ago, nanomaterials have found use worldwide. Carbon nanotubes (CNTs) are one of the most widely known members of the nanomaterial family. Based on their structure, CNTs are classified into single-walled CNTs (SWCNTs) and multi-walled CNTs. Their unique physicochemical properties make CNTs a good choice for a variety of applications, such as in sporting goods, automobile products, and household items. ${ }^{1}$ Notably, CNTs hold great promise for in vivo medical applications. ${ }^{2,3}$

CNTs have attracted increasing attention in medical neurosciences. CNT-based electrodes not only show high sensitivity in detecting current change, ${ }^{4}$ but are also applied to electrical nerve stimulation as a treatment for nervous system diseases because of their unique electrical conductivity. ${ }^{5}$ When used in nerve cell growth scaffolds, CNTs provide a perfect cell-material interface for cell growth and differentiation, whereby the scaffolds can enhance the adherence rate to cells, improve cell vitality, and induce stem cell differentiation into mature nerve cells. ${ }^{6-8}$ Because of their strong ability to cross cell membranes, ${ }^{9}$ CNTs have been reported to deliver drugs or genes into brain 
nerve cells for the treatment of glioma ${ }^{10}$ or neurodegenerative diseases such as Alzheimer's disease. ${ }^{11}$

With the increasing use of CNTs, the possibility of exposure to CNTs also rises significantly, and thus the safety of CNTs to biological systems has become a major concern for their further application. Several biocompatibility studies have shown that CNTs can accumulate in organs, ${ }^{12}$ generate oxidative stress, ${ }^{13,14}$ and damage cells ${ }^{15}$ and organs such as the lung, heart, and testes. ${ }^{16-18}$ However, there is a lack of data regarding the potential neurotoxic effects of CNTs, especially from in vivo studies.

Several in vitro studies have demonstrated the neurotoxic effects of CNTs, including a cell viability decrease and the induction of both oxidative stress and apoptosis. ${ }^{19,20}$ However, the cell type influenced the uptake, localization, and cytotoxicity of nanoparticles in an in vitro study. ${ }^{21}$ In addition, physicochemical characterization, in vitro assays, and in vivo studies are regarded as the three key elements of a toxicity screening strategy for nanoparticles. ${ }^{22}$ Hence, systematic in vivo studies mimicking the possible effects in humans are urgently required to ensure the safe use of CNTs in biomedicine, especially in the nervous system.

In this study, behavioral changes in mice after exposure to SWCNTs were detected, and the key upstream events for resulting damage were examined to explore the possible mechanisms. Mouse neuroblastoma cells were also employed to verify the mechanism in vitro (Figures S1 and S2). The ultimate aim of this study was to define the damage in mouse brains after SWCNT exposure and to investigate a suitable protective agent to avoid damage caused by SWCNTs, thus ensuring the safe medical application of SWCNTs in the nervous system.

\section{Material and methods}

\section{Animals}

Specified pathogen-free class male Kunming mice (5-6 weeks old, 22 $\pm 2 \mathrm{~g}$ ) were purchased from the Hubei Province Experimental Animal Center (Wuhan, People's Republic of China) and housed in standard environmental conditions (12 hours light-dark cycle, 50\%-70\% humidity, and $20^{\circ} \mathrm{C}-25^{\circ} \mathrm{C}$ ). Food and water were provided ad libitum. Mice were quarantined for $\geq 7$ days before study initiation. Nine mice in each group were used, to minimize the number of experimental animals needed, while ensuring the validity of statistical analyses. All experimental procedures were approved by the Office of Scientific Research Management of Central China Normal University (Wuhan, People's Republic of China), with a certificate of Application for the Use of Animals dated March 1, 2012 (approval ID: CCNU-IACUC-2012-011).

\section{Reagents and kits}

SWCNTs, 2',7'-dichlorodihydrofluorescein diacetate (DCFH-DA), 2-thiobarbituric acid (TBA), 3-carboxy-4nitrophenyl disulfide (DTNB), and ascorbic acid were purchased from Sigma-Aldrich (St Louis, MO, USA). All other chemicals were of the highest grade available commercially. A mouse enzyme-linked immunosorbent assay (ELISA) kit for nuclear factor (NF)- $\kappa$ B was purchased from Blue Gene (Shanghai, People's Republic of China). Mouse ELISA kits for tumor necrosis factor (TNF)- $\alpha$ and interleukin (IL)-1 $\beta$ were purchased from eBioscience (San Diego, CA, USA). The mouse caspase-3 activity assay kit was purchased from Beyotime (Nanjing, Jiangsu, People's Republic of China).

\section{Preparation of SWCNTs}

The SWCNTs were dispersed in $0.9 \% \mathrm{NaCl}$ with $0.1 \%$ Tween 80 , and the suspensions were sonicated for 10 minutes before use.

\section{Characterization of SWCNTs}

SWCNTs were synthesized by the chemical vapor deposition method. The physical and chemical properties of SWCNTs were characterized by scanning electron microscopy (SEM), transmission electron microscopy (TEM), X-ray photoelectron spectroscopy (XPS), atomic force microscopy (AFM), and Raman spectroscopy. The shapes of SWCNTs were characterized using SEM (JEOL-6700F; JEOL, Tokyo, Japan) and TEM (JEM-2010; JEOL). Morphology of the SWCNTs was captured using AFM (Dimension Icon ${ }^{\circledR}$; Brucker Corporation, Billerica, MA, USA) with tapping mode at ambient temperature. Trace amounts of metal were detected by XPS (ESCLAB 250Xi; Thermo Scientific, Waltham, MA, USA). Raman spectra were collected using a Raman Microscope (Renishaw inVia Plus; Renishaw, Hoffman Estates, IL, USA) with a $50 \times$ air objective lens and a $514 \mathrm{~nm}(1.96 \mathrm{eV})$ laser wavelength.

\section{Experimental protocol}

Mice were divided randomly into six experimental groups of nine animals. These groups were exposed to $0,3.125,6.25$, and $12.5 \mathrm{mg} / \mathrm{kg} /$ day SWCNTs ${ }^{23} 6.25 \mathrm{mg} /$ $\mathrm{kg}$ /day SWCNTs $+100 \mathrm{mg} / \mathrm{kg} /$ day ascorbic acid (block group), and $100 \mathrm{mg} / \mathrm{kg} /$ day ascorbic acid. ${ }^{24}$ We intravenously injected the suspension daily through the tail vein. ${ }^{18}$ Based on the period of ethological analysis we adopted in this study, 
SWCNTs were administered for 9 days. ${ }^{25}$ The first to seventh days were the hidden-platform acquisition test, the eighth day was the forgetting-period, and the ninth day was the probe trial test and open-field test (OFT) (Figure 1A).

\section{Morris water maze}

The Morris water maze (MWM) was conducted to investigate the cognitive ability of the mice. Mice were placed in a circular, featureless pool of cool opaque water, where they had to swim until they discovered the escape platform (which was invisible and beneath the water surface). The mice were allowed to rest on the platform before returning to the water for another attempt. After several days of training, the rodents learned to swim directly onto the platform, presumably by using spatial cues from the room as a reference. The biomarkers for the MWM were "escape latency" for learning and "swimming time in the southeast (SE) quadrant (searchto-platform area)" for memory. The biomarkers were used to ascertain the learning ability from the first to the seventh day and to measure memory ability by the search-to-platform area on the ninth day. ${ }^{25}$ The equipment of the MWM is shown in Figure $1 \mathrm{~B}$ and Table 1.

The training began 4 hours after the end of the daily exposure of the mice. The mice were released into the water from the northeast (NE), northwest (NW), and southwest (SW) quadrants, near to and facing the wall; each mouse had three trials per day. Each training session had a maximum duration of 60 seconds. If a mouse could not find the platform within
60 seconds, the escape latency was recorded as 60 seconds, and the mouse was led to the platform and placed on it for 30 seconds; this training continued until the seventh day. The first 7 days were used for the hidden-platform acquisition test to detect the learning ability of the mice. On the eighth day, the water maze was not used, allowing a period for the mice to forget the location of the platform. On the ninth day, the water maze was again used, but the platform was removed from the pool to detect the memory ability of the mice. The mice were put into the pool from the NE, NW, and SW quadrants for the probe trial test also, and the camera recorded their tracks for 60 seconds.

\section{OFT}

The OFT is one of the most popular tests in neuroscience. The equipment of the MWM is shown in Table 1. The locomotor activity of the mice was assessed using an openfield, the methodological details for which have been given by Davis et al. ${ }^{26}$ Briefly, the apparatus consisted of a square base $(40 \mathrm{~cm} \times 40 \mathrm{~cm})$ surrounded by a $35 \mathrm{~cm}$ wall, with the floor divided into 16 squares. The "border" was defined as the 12 outer periphery squares of the 16 squares, and the "center" as the four squares in the center area. On the ninth day, each mouse was placed individually in the center of the open-field apparatus. Testing was conducted over 5 minutes (300 seconds), and recorded using a video tracking system. The walls and floors of the apparatus were cleaned thoroughly between tests with $10 \%$ ethanol.
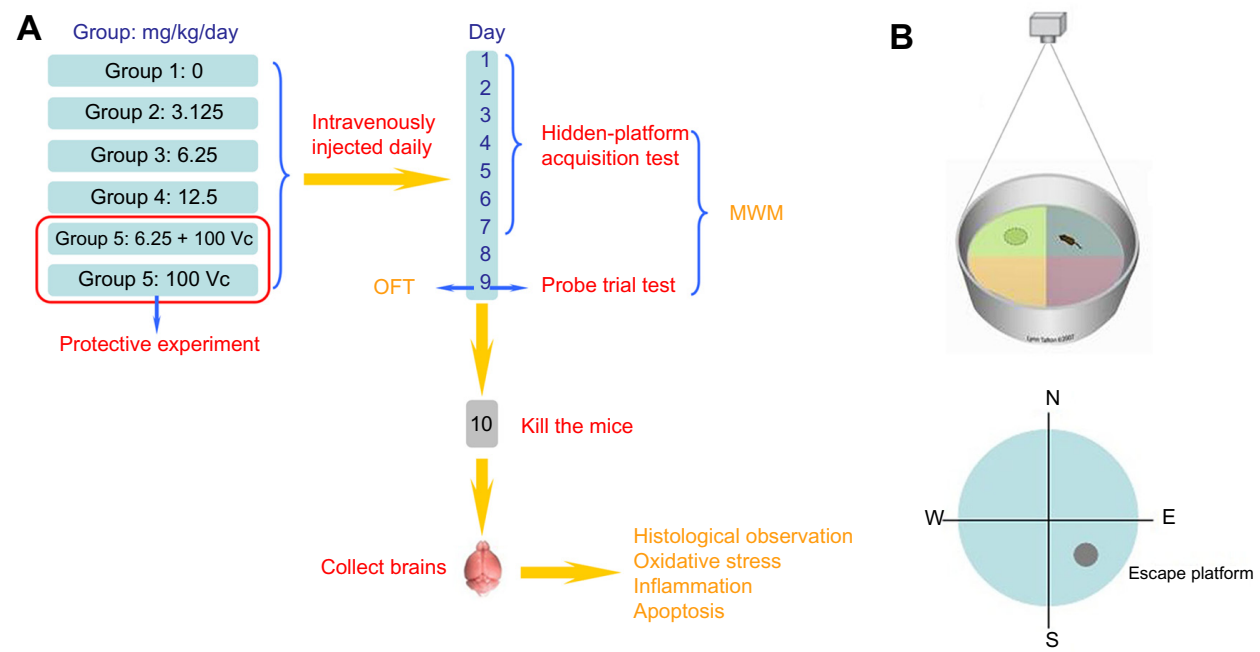

Figure I The experimental protocol and the MWM devices used in this study. (A) The experimental protocol.

Notes: Six groups of mice were intravenously injected with SWCNTs daily for 9 days. From the first day to the seventh day was the hidden-platform acquisition test, the eighth day was the forgetting-period; and the ninth day was the probe trial test. OFT was also carried out on the ninth day. Then, on the tenth day, the mice were sacrificed and their brains collected for subsequent analysis. (B) Morris water maze devices. The water maze was a $100 \mathrm{~cm}$ diameter pool, filled with water containing white paint (with negligible toxicity) to a depth of $20 \mathrm{~cm}$. The water was kept at room temperature $\left(23^{\circ} \mathrm{C} \pm \mathrm{I}^{\circ} \mathrm{C}\right)$. The pool was divided into four quadrants, and the platform was placed $\mathrm{I} \mathrm{cm}$ below the water surface, in the center of the SE quadrant. A camera recorded the tracks of the mice.

Abbreviations: MWM, Morris water maze; OFT, open-field test; SE, southeast; SWCNT, single-walled carbon nanotube; Vc, ascorbic acid. 
Table I Equipment for ethological analysis

\begin{tabular}{lllll}
\hline Equipment (model) & Manufacturer & Software used & Bio-effects tested & Endpoints tested \\
\hline Morris water maze & Wuhan Yi-Hong Sci \& Tech & ANY-Maze ${ }^{\mathrm{TM}}$ (Stoelting & Cognitive ability & Search-to-platform \\
& $\begin{array}{l}\text { Co, Ltd (Wuhan, People's } \\
\text { Republic of China) }\end{array}$ & area & \\
Wuhan Yi-Hong Sci \& Tech & ANY-Maze ${ }^{\mathrm{TM}}$ & Locomotor activity & $\begin{array}{l}\text { Travel in the center } \\
\text { Open-field test }\end{array}$ \\
Co, Ltd & & & or border \\
\hline
\end{tabular}

\section{Brain histological assay}

Twenty-four hours after the intravenous injection on the ninth day, the mice were sacrificed by cervical dislocation and the brains collected. Brains were incubated in fixative (saturated 2,4,6-trinitrophenol/formalin/glacial acetic acid $[15: 5: 1 \mathrm{v} / \mathrm{v} / \mathrm{v}])$ for 24 hours at room temperature. Hematoxylin and eosin (H\&E)- and Nissl-stained slices were then prepared as previously described. ${ }^{27,28}$ Stained pieces were embedded in paraffin, sectioned into $10 \mu \mathrm{m}$ slices, and observed using a DM 4000B microscope (Leica, Berlin, Germany). The average optical density (OD) of each slice was determined using Image-Pro Plus 6.0 (Media Cybernetics, Bethesda, MD, USA) software. A non-stained region was selected and set as the background. All tissue sections were examined qualitatively by two experienced pathologists in a blinded fashion.

\section{Tissue sample preparation}

The collected brains were weighed in a completely automatic electronic balance. Tissue was placed in $10 \mathrm{~mL} / \mathrm{g}$ ice-cold $1 \times$ phosphate-buffered saline (PBS, $\mathrm{pH}=7.5$ ) and homogenized using a glass homegenizer. Homogenate was centrifuged at $10,000 \mathrm{rpm}$ for 10 minutes at $4^{\circ} \mathrm{C}$. The supernatant was collected and frozen at $-70^{\circ} \mathrm{C}$ until assayed; the protein concentration of supernatant was determined using the Lowry assay. ${ }^{29}$

\section{Detection of reactive oxygen species}

Reactive oxygen species (ROS) was measured using oxidation-sensitive fluorescent DCFH-DA, which is a nonfluorescent compound that is freely taken up by cells and hydrolyzed by esterases to 2',7'-dichlorodihydrofluorescein (DCFH). DCFH is then oxidized to the fluorescent dichlorofluorescein (DCF) in the presence of peroxides, thereby indicating the level of intracellular ROS. ${ }^{30}$ Briefly, the supernatant was diluted ten times with PBS ( $\mathrm{pH}=7.5$ ), then $100 \mu \mathrm{L}$ was removed to a 96 -well microplate, and $100 \mu \mathrm{L}$ of $10 \mu \mathrm{mol} / \mathrm{L}$ DCFH-DA was added. The reaction mixture was kept in the dark for 30 minutes at $37^{\circ} \mathrm{C}$, then the fluorescence intensity was measured at an excitation wavelength of $488 \mathrm{~nm}$ and an emission wavelength of $525 \mathrm{~nm}$ by a fluorescence reader (FLx 800; BioTek Instruments, Vinooski, VT, USA).

\section{Measurement of malondialdehyde}

Malondialdehyde (MDA) can react with TBA to form a stable chromophoric production, which can be used to measure the concentration of MDA. Briefly, $2 \mathrm{~mL} 0.6 \%$ TBA solution (dissolved in $10 \%$ trichloroacetic acid) was added into $0.5 \mathrm{~mL}$ supernatant and incubated in boiling water for 15 minutes; proteins were precipitated, and pink pigments formed in the mixture. The mixture was cooled and centrifuged at 10,000 rpm for 5 minutes at $4^{\circ} \mathrm{C}$. The supernatant was collected, and absorbance measured at 532, 600, and $450 \mathrm{~nm}$. The concentration of MDA was calculated as $\operatorname{MDA}(\mu \mathrm{mol} / \mathrm{L})=6.45 \times\left(\mathrm{OD}_{532}-\mathrm{OD}_{600}\right)-0.56 \times \mathrm{OD}_{450}{ }^{31}$

\section{Glutathione depletion assay}

Glutathione (GSH) can react with DTNB in the dark and produces 2-nitro-5-thiobenzoic acid (TNB). In case of disturbance by thiols in proteins, $10 \%$ trichloroacetic acid was used to delimitate these proteins. Afterwards, the $\mathrm{pH}$ was adjusted to 7.5 to yield the color-change reaction with DTNB $(60 \mu \mathrm{g} / \mathrm{mL}), 50 \mu \mathrm{L}$ supernatant was transferred into the 96-well microplate, $150 \mu \mathrm{L}$ of DTNB added, and then incubated in the dark at room temperature for 5 minutes. Experimental and standard samples were analyzed using a microplate reader at a wavelength of $412 \mathrm{~nm} .{ }^{32}$ Based on the standard curve, the calculation was $\mathrm{GSH}(\mathrm{nmoL} /$ $\mathrm{L})=\mathrm{OD}_{412} / 0.0023, R^{2}=0.997$.

\section{Analysis of NF- $\kappa B$, TNF- $\alpha$, and IL-I $\beta$ content, and caspase- 3 activity}

The supernatant (mentioned in "Tissue sample preparation" previously) was used to detect the concentration of NF- $\mathrm{kB}$, TNF- $\alpha$, and IL- $1 \beta$. The concentrations were measured using ELISA kits according to the manufacturers' instructions. The sensitivities of the ELISA kits were $0.1 \mathrm{ng} / \mathrm{mL}$ for NF- $\mathrm{KB}$, $8 \mathrm{pg} / \mathrm{mL}$ for TNF- $\alpha$, and $80 \mathrm{pg} / \mathrm{mL}$ for IL- $1 \beta$. The activation of caspase- 3 was determined with the caspase-3 assay kit. This assay is based on spectrophotometric detection of the chromophore p-nitroanilide ( $p$ NA) after its cleavage from the labeled substrate acetyl-Asp-Glu-Val-Asp $P$-nitroanilide (DEVD-pNA). Caspase-3 activities were determined 
according to the manufacturer's instructions. Absorbance of the chromophore $p$ NA produced was measured at $405 \mathrm{~nm}$.

\section{Statistical analysis}

Analysis of variance (ANOVA) was applied for statistical analysis. Statistical graphs were generated using Origin 8.0 (OriginLab, Berkeley, CA, USA) software. Statistical analyses were carried out using SPSS (SPSS, Chicago, IL, USA) software, version 13.0. A repeated measures ANOVA followed by a post hoc test named as Tukey was used for the MWM escape latency analyses; and all other data were analyzed by a one-way ANOVA followed by Tukey test. A $P$-value of $<0.05$ was considered a significant difference.

\section{Results}

\section{Characterization of SWCNTs}

SWCNTs were characterized using SEM, TEM, AFM, XPS, and Raman spectroscopy to ascertain their quality. SEM images showed that the structure of the SWCNTs we used was a smooth tube shape (Figure 2A). TEM images showed a single-walled tube structure of materials (Figure 2B). XPS analysis revealed that the main metal catalysts were negligible in the SWCNT samples tested (Figure S3). In addition, the structure and purity of the SWCNTs were further analyzed by Raman scattering analysis. Raman spectra (Figure 2C) measurement using $514 \mathrm{~nm}$ excitation showed that $\mathrm{G} / \mathrm{D}$ ratios were 15.64. Raman radial breathing mode peak analysis indicated that the diameter of SWCNTs ranged from 0.88 to $1.56 \mathrm{~nm}$. An AFM image was captured to characterize the diameter and the length of the SWCNTs (Figure S4). It was observed that the diameter of the SWCNTs was around $1.0 \mathrm{~nm}$, which is consistent with the Raman results. In addition, the length of the SWCNTs was around $1.38 \mu \mathrm{m}$. Characterization data showed that the quality of the SWCNTs perfectly met the requirements of subsequent experiments.

\section{MWM}

The cognitive ability of the mice after SWCNT exposure is shown in Figure 3; throughout 7 days of training, a reduction in the escape latency (the time to find the platform) was observed in each group (Figure 3A). The latency of the control group had the fastest decrease (fastest learning) (slope $=-5.82$ seconds/day, $P<0.01$ ), whereas that of the $12.5 \mathrm{mg} / \mathrm{kg} /$ day group had the slowest decrease (slowest learning) (slope $=-3.56$ seconds/day, $P<0.01$ ). A significant increase in average escape latency for 7 days was detected in the mice from the 6.25 and $12.5 \mathrm{mg} / \mathrm{kg} /$ day groups compared with the mice from the control group (Figure 3A). After the forgetting-period (the eighth day), on the ninth day, the spatial memories of the mice were evaluated. The time (in seconds) of each mouse remaining in the target quarter (SE quarter) were different, mice in the 6.25 and $12.50 \mathrm{mg} / \mathrm{kg}$ /day groups were significantly decreased (Figure 3B), and the frequency into or out from the target quarter showed the same trend (Figure 3C). However, mice in the $3.125 \mathrm{mg} / \mathrm{kg} /$ day group did not change significantly in all these items. From the data of the ninth day (Figure 3D), it is clear that the route taken by the mice in the control and $3.125 \mathrm{mg} / \mathrm{kg} /$ day groups were purposeful, orderly, and focused on the target quadrant (SE), while the routes taken by the mice in the other groups were irregular and apparently without purpose.

\section{OFT}

The locomotor activity of the mice after SWCNT exposure is shown in Figure 3. There was a significant reduction in the total distance traveled by the mice from the $6.25 \mathrm{mg} / \mathrm{kg} / \mathrm{day}$ and $12.5 \mathrm{mg} / \mathrm{kg} /$ day groups compared with the mice from the control group (Figure 3E). Figure 3F-I show that after SWCNT exposure, the mice travelling in the border area took longer and ran a greater distance. The defecation number (Figure $3 \mathrm{H}$ ) also showed a significant increase in these groups. However, the results for the mice
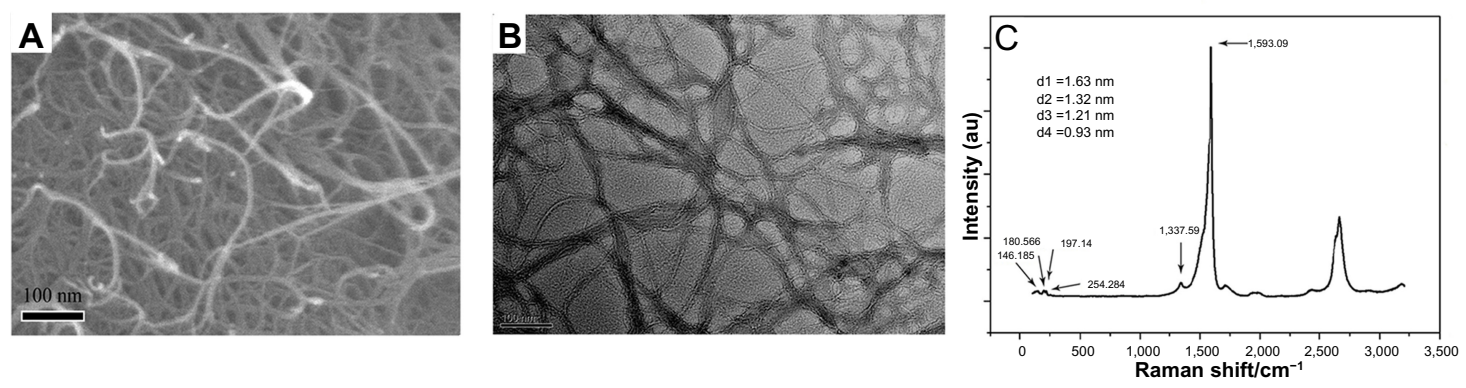

Figure 2 Characterization of SWCNTs.

Notes: (A) Scanning electron microscopy image of SWCNTs. (B) Transmission electron microscopy images of SWCNTs. (C) Raman spectra of SWCNTs. Abbreviations: SWCNT, single-walled carbon nanotube; d, reciprocal wavelength; au, arbitrary units. 
A Morris water maze

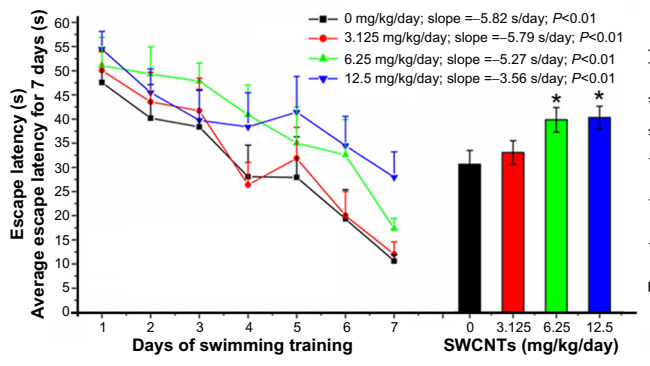

B

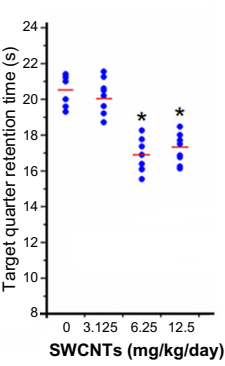

C

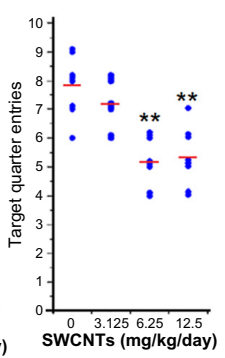

D

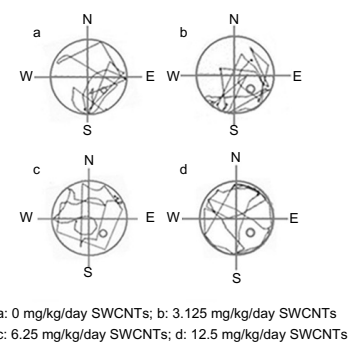

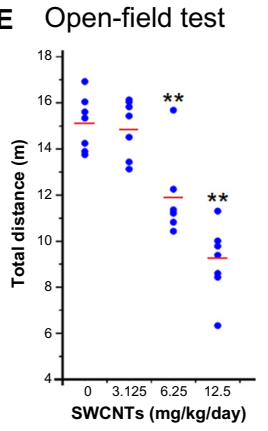

$\mathbf{F}$

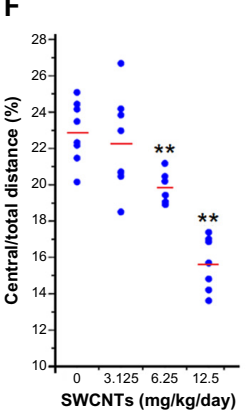

G

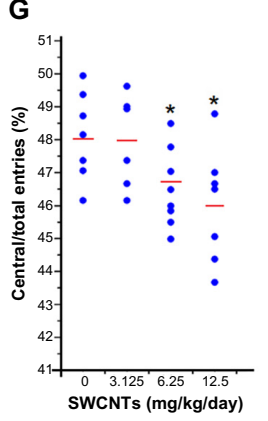

H

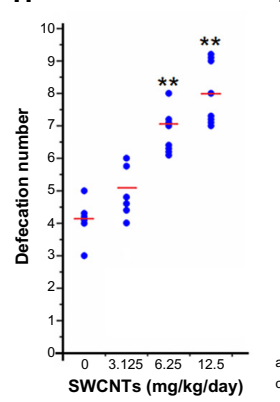

I

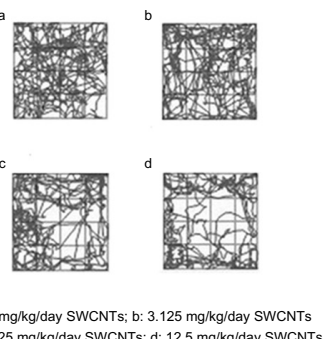

Figure 3 Morris water maze test (A-D), and open-field test (E-I) after SWCNT exposure.

Notes: (A) The escape latency for first 7 days. (B) The swimming time in the target quadrant on the ninth day. (C) The number of target quadrant entries on the ninth day. (D) The swimming route of different exposure groups on the ninth day. (E) The total travel distance in the open-field. (F) The proportion of central/total distance. (G) The proportion of central/total entry times. (H) The defecation number. (I) Routes of the mice in the open-field. $* P<0.05$; $* * P<0.01$, compared with the control group $(0 \mathrm{mg} / \mathrm{kg} /$ day SWCNTs). Slope analyses were taken by Origin 8.0 (OriginLab, Berkeley, CA, USA) software.

Abbreviations: SWCNT, single-walled carbon nanotube; s, seconds.

in the $3.125 \mathrm{mg} / \mathrm{kg} /$ day group showed no significant change compared with the mice in the control group.

\section{Histological observation of mouse brains}

After the MWM and OFT, mouse brains were collected for histological observation. Through H\&E staining (Figure 4, A1-A4), we found that pyramidal cells in the hippocampus $\mathrm{CA}_{1}$ region of mice from the control group (Figure A1) were arranged in a tidy manner, wherein polygonalshaped cells with clear edges were stretched in radial apical dendrites to the inner hippocampus. With increasing exposure concentrations (Figure A2-A4), there appeared to be pathological alterations in that the arrangement of cells became loose and disordered, with swelling deformations in cell shape and shortening or even the disappearance of apical dendrites. Nissl staining shown in Figure 4B, clearly demonstrates the neat arrangement and clear cytoplasmic staining of cells in the control group (Figure B1), and the increase in Nissl substance with increasing exposure concentrations (Figure B2-B4) caused by damage to cells in a dose-dependent manner. Decreases in average OD were observed in the mice from the 6.25 and $12.50 \mathrm{mg} / \mathrm{kg} /$ day groups compared with the
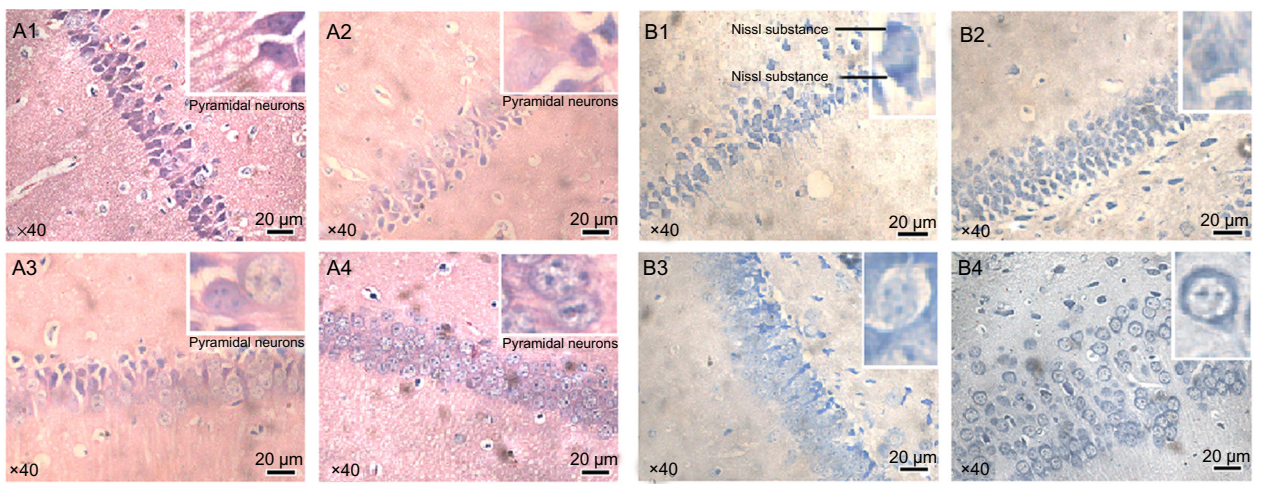

Figure 4 Histological observation $(\times 40)$ of mouse brains after SWCNT exposure. (AI-A4) Hematoxylin and eosin staining. (B I-B4) Nissl staining. Notes: In (AI-A4) and (B I-B4), each of the four images represent the four different exposure groups, 0, 3.I25, 6.25, and I2.5 mg/kg/day SWCNTs, respectively. Inset images are higher magnification views of the positively stained cells, demonstrating normal cells in the control group ( $\mathrm{Al}$ and $\mathrm{BI})$, and abnormal cells in the other groups. Abbreviation: SWCNT, single-walled carbon nanotube. 
mice from the control group (Figure S5A), but mice from the $3.125 \mathrm{mg} / \mathrm{kg} /$ day group showed no significant change.

\section{Oxidative stress level}

After ethological analysis and histological observation, the oxidative stress level in mouse brains was detected to explore the possible mechanisms of damage in mouse brains after exposure to SWCNTs. A significant increase in ROS level, which is the most important biomarker for oxidative stress, was observed in the mice of all exposure groups (Figure 5A). ROS can be associated with lipid peroxidation of unsaturated fatty acids in the plasma membrane. Compared with that of the mice in the control group, the MDA content of the mice in the 6.25 and $12.50 \mathrm{mg} / \mathrm{kg} /$ day groups increased significantly, but mice in the $3.125 \mathrm{mg} / \mathrm{kg} /$ day group did not change noticeably (Figure 5B). GSH can scavenge ROS molecules to prevent oxidation. Figure 5C shows this GSH reduction. There was a significant reduction in GSH content in the mice in the 6.25 and $12.50 \mathrm{mg} / \mathrm{kg} /$ day groups; the mice from the $3.125 \mathrm{mg} / \mathrm{kg} /$ day group did not change.

\section{Inflammation and apoptosis}

The inflammation and apoptosis levels are shown in Figure 5. The expression levels of NF- $\kappa \mathrm{B}$, a redox-sensitive transcription factor, in the 6.25 and $12.50 \mathrm{mg} / \mathrm{kg} /$ day groups increased significantly (Figure 5D). NF- $\mathrm{kB}$ can convert oxidative stress signals into changes in gene expression associated with diverse cellular activities, such as induced expression of TNF- $\alpha$ and IL- $1 \beta$. The expressions of TNF- $\alpha$ and IL- $1 \beta$ in this study demonstrated similar trends to that of NF- $\mathrm{KB}$, with both increasing significantly (Figure 5E and F). Caspase-independent mechanisms are some of the most important mechanisms of apoptosis. A significant increase was observed in the activation of caspase-3 compared with that in the mice in the control group (Figure 5G). However, SWCNTs had no effect on any of these biomarkers at a dose of $3.125 \mathrm{mg} / \mathrm{kg} /$ day.

\section{The neuroprotective effects of ascorbic acid}

Ascorbic acid is a water-soluble vitamin with antioxidant properties that is readily absorbed by organisms. After ascorbic acid protection, we found that, in the MWM on the seventh day, compared with the mice in the $6.25 \mathrm{mg} / \mathrm{kg} /$ day group, the mice in the block group spent shorter times finding the platform (Figure 6A). They made their way more easily into the target quadrant and spent longer times in the target quadrant (Figure 6B and C), with more

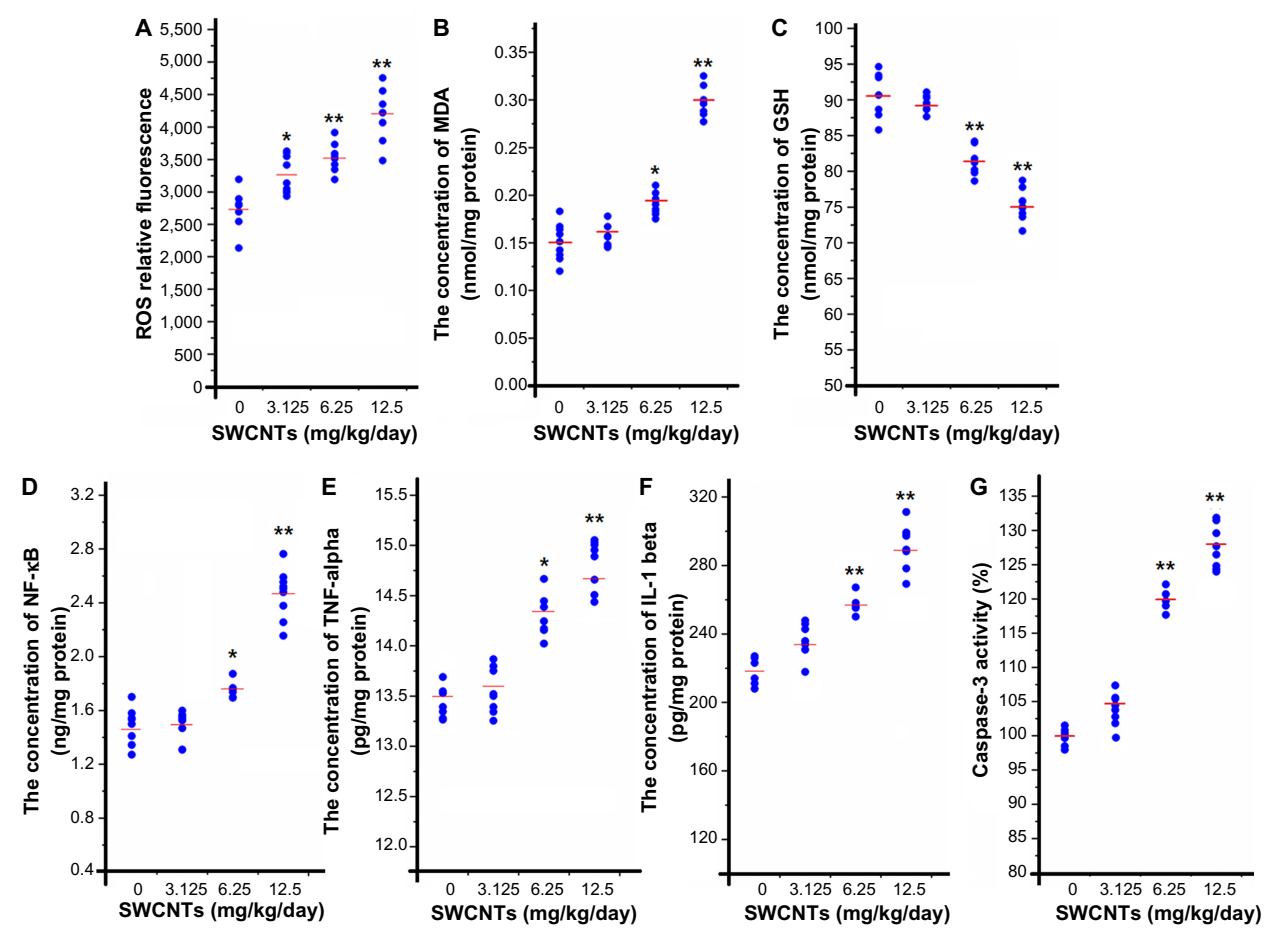

Figure $\mathbf{5}$ The oxidative stress, inflammation, and apoptosis levels in the mouse brains after SWCNT exposure.

Notes: (A) The relative fluorescence of ROS. (B) The concentration of MDA. (C) The concentration of GSH. (D) The concentration of NF- $\kappa B$. (E) The concentration of TNF- $\alpha$. (F) The concentration of IL-I $\beta$. (G) The activity of caspase-3. $* P<0.05$; $* * P<0.0$ I, compared with the control group $(0 \mathrm{mg} / \mathrm{kg} / \mathrm{day}$ SWCNTs).

Abbreviations: GSH, glutathione; IL-I $\beta$, interleukin I $\beta$; MDA, malondialdehyde; NF- $\kappa B$, nuclear factor $\kappa B$; ROS, reactive oxygen species; SWCNT, single-walled carbon nanotube; TNF- $\alpha$, tumor necrosis factor $\alpha$. 

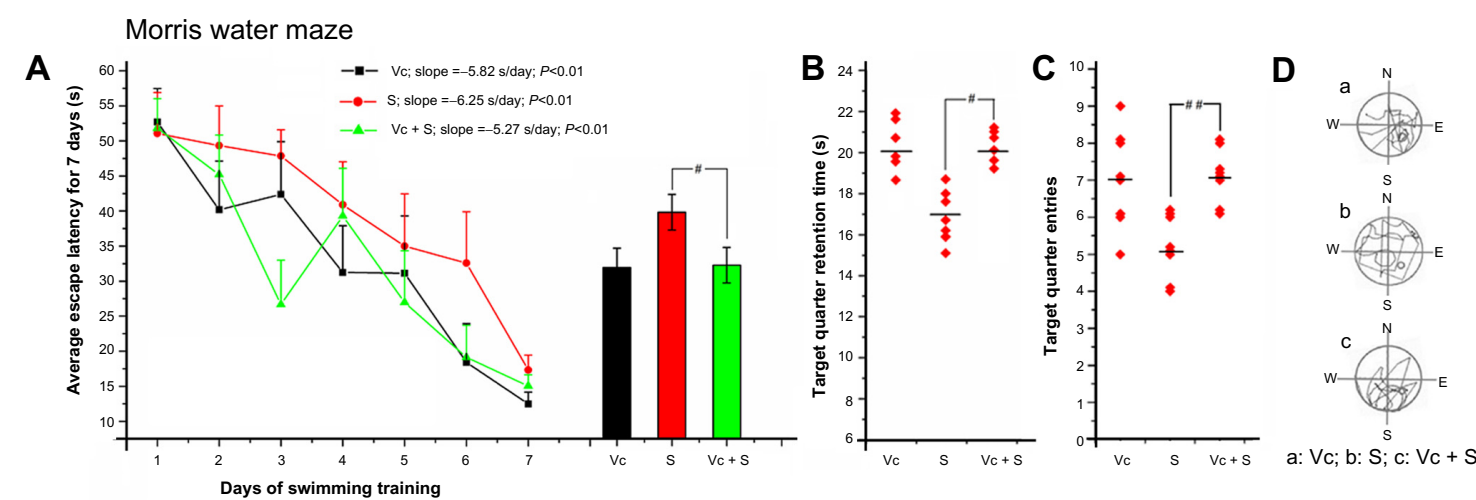

E

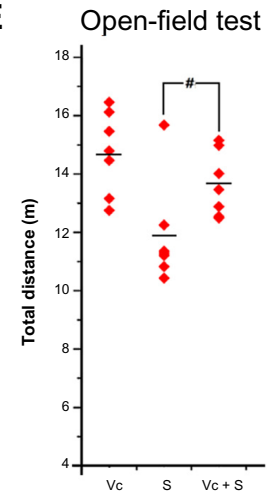

$\mathbf{F}$

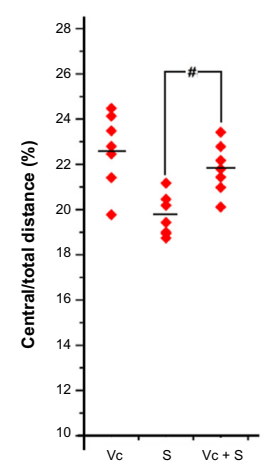

G

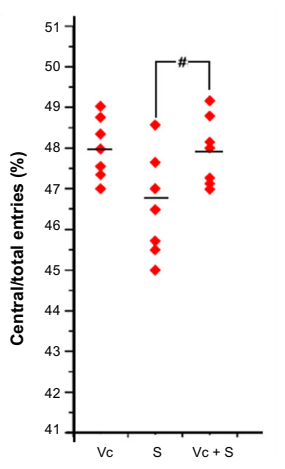

H

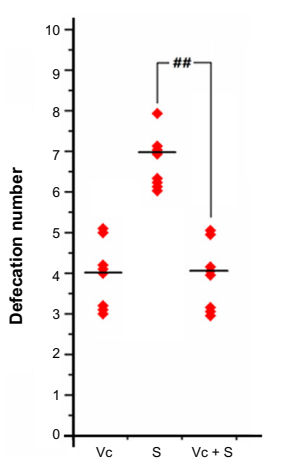

I

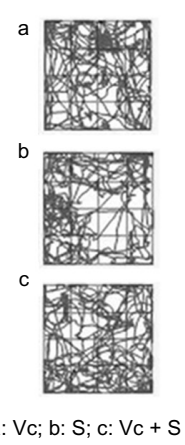

Figure 6 The protective effects of ascorbic acid in the Morris water maze test (A-D) and in the open-field test (E-I).

Notes: (A) The escape latency of different exposure groups for the first 7 days. (B) The swimming time in the target quadrant of different groups on the ninth day. (C) The number of target quadrant entries on the ninth day. (D) The swimming route on the ninth day. (E) The total travel distance in the open-field. (F) The proportion of central/total distance. (G) The proportion of central/total entry times. (H) The defecation number. (I) Route of the mice in the open-field. $\# P<0.05$; \# $P<0.0 \mathrm{I}$, comparisons between the 6.25 mg/kg/day SWCNTs group and the block group $(6.25 \mathrm{mg} / \mathrm{kg} /$ day SWCNTs + $100 \mathrm{mg} / \mathrm{kg} /$ day ascorbic acid). Slope analyses were taken by Origin 8.0 (OriginLab, Berkeley, CA, USA) software.

Abbreviations: SWCNT, single-walled carbon nanotube; S, SWCNT; Vc, ascorbic acid; s, seconds.

direct routes, which were orderly in shape and focused on the SE quadrant (Figure 6D). In OFT, compared with the mice in the $6.25 \mathrm{mg} / \mathrm{kg} /$ day group, the mice in the block group traveled longer distances in the open-field (Figure 6E), were more inclined to enter into the central area (Figure 6F-I), and had a significant reduction in defecation number (Figure 6H).

Histological observations after ascorbic acid protection (Figure 7A and B) showed that although there still appeared to be damaged cells in the block group (A3), the amount
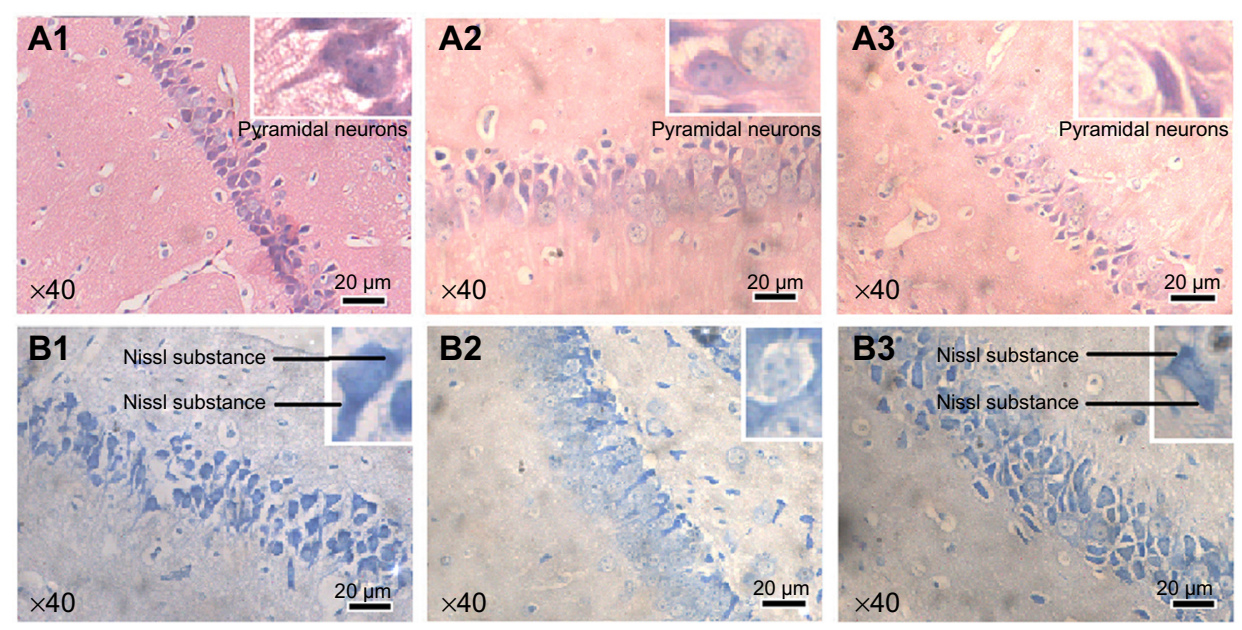

Figure 7 Histological observation $(\times 40)$ of mouse brains after ascorbic acid protection. (AI-A3) Hematoxylin and eosin staining. (B I-B3) Nissl staining.

Notes: In (AI-A3) and (BI-B3), each of the three images represent the three different exposure groups, $100 \mathrm{mg} / \mathrm{kg} / \mathrm{day}$ ascorbic acid, $6.25 \mathrm{mg} / \mathrm{kg} / \mathrm{day} \mathrm{SWCNTs}$, $6.25 \mathrm{mg} / \mathrm{kg} /$ day SWCNTs $+100 \mathrm{mg} / \mathrm{kg} /$ day ascorbic acid, respectively. Inset images are higher magnification views of the positively stained cells, demonstrating normal cells in the control group (AI and $\mathrm{BI}$ ), and abnormal cells in the other groups.

Abbreviation: SWCNT, single-walled carbon nanotube. 
was much lower than that of the $6.25 \mathrm{mg} / \mathrm{kg} /$ day group, and most cells in the block group remained intact and were stained homogeneously. Nissl staining results (Figure 7B) immediately showed that Nissl substance loss was lower in the mice from the block group (B3) (Figure S3B).

As shown in Figure 8A, the amount of ROS generated was lower in the mice from the block group than that in the mice from the $6.25 \mathrm{mg} / \mathrm{kg} /$ day group. Meanwhile, the GSH level of the mice in the block group was significantly higher than that of the mice in the $6.25 \mathrm{mg}$ / $\mathrm{kg}$ /day group (Figure $8 \mathrm{~B}$ ). The expression of NF- $\mathrm{KB}$ in the mice from the block group was lower than that in the mice from the $6.25 \mathrm{mg} / \mathrm{kg} /$ day group (Figure $8 \mathrm{C}$ ). The release of TNF- $\alpha$ and IL- $1 \beta$ in the mice from the block group was lower compared with the mice from the 6.25 $\mathrm{mg} / \mathrm{kg}$ /day group (Figure 8D and E); and the level of caspase- 3 activation in the mice from the block group was lower than that of the mice from the $6.25 \mathrm{mg} / \mathrm{kg} /$ day group (Figure 8F).

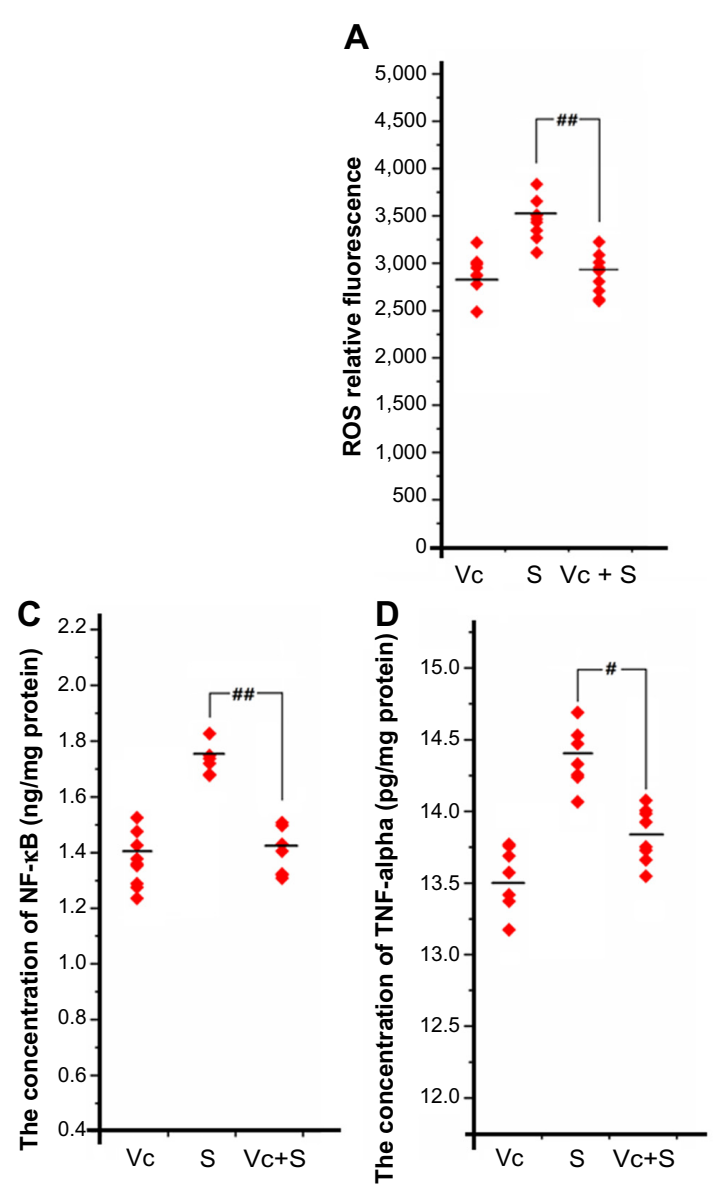

\section{Discussion}

As one of the most prominent nano-objects, SWCNTs hold a great promise for application in medical neurosciences, hence systematic in vivo studies are urgently required to ensure the safe use of SWCNTs in the nervous system. In this study, we evaluated damage to mouse brains after exposure to certain SWCNTs and investigated the suitability of a protective agent to avoid damage caused by higher dosages.

After exposure to SWCNTs, ethological analysis (MWM and OFT) of the mice showed behavioral changes. The results from the MWM test indicate that SWCNT exposure can negatively affect the cognitive abilities of mice. After 7 days of training, the mice from both the 6.25 and the $12.50 \mathrm{mg} / \mathrm{kg} /$ day groups required longer times to find the escape platform. In other words, the learning abilities of the mice from these groups were undermined to differing extents. In addition, for the mice from these two groups, both the number of SE quadrant entries and the time spent in the target quadrant decreased, and their swimming routes became irregular and
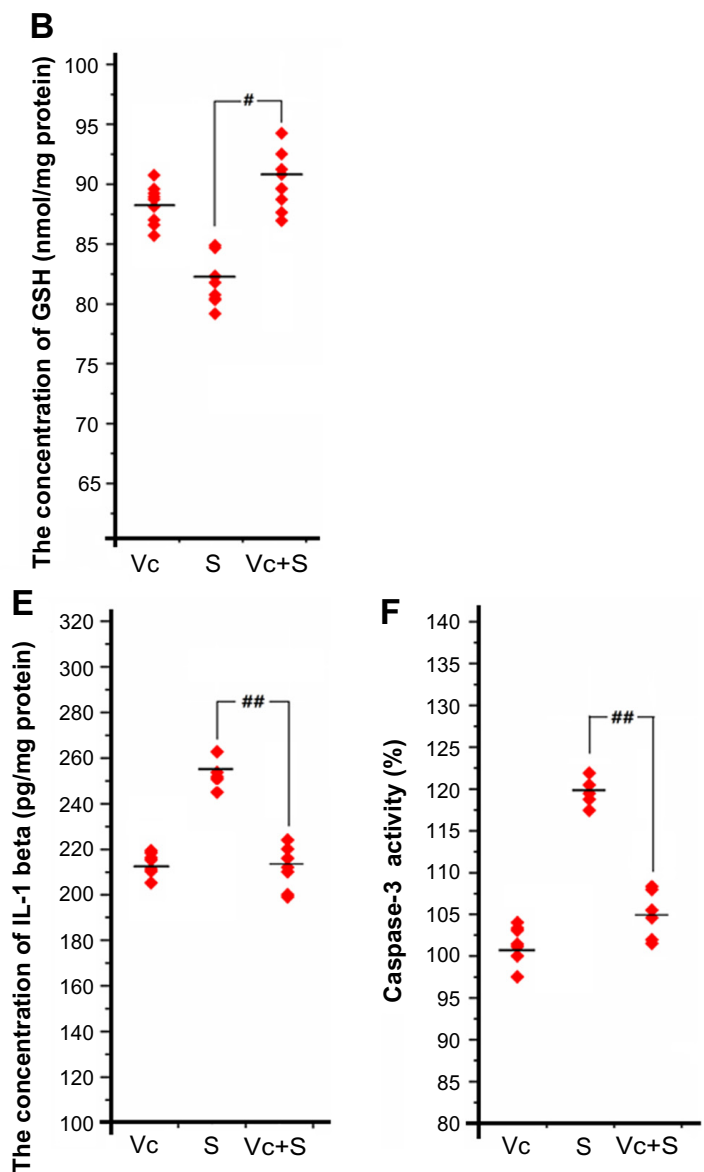

Figure 8 The oxidative stress, inflammation, and apoptosis levels in mouse brains after ascorbic acid protection.

Notes: (A) The relative fluorescence of ROS. (B) The concentration of GSH. (C) The concentration of NF-KB. (D) The concentration of TNF- $\alpha$. (E) The concentration

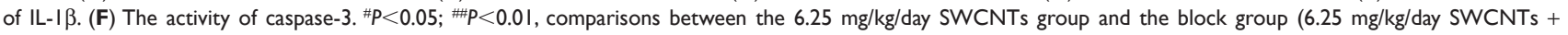
$100 \mathrm{mg} / \mathrm{kg} /$ day ascorbic acid).

Abbreviations: GSH, glutathione; IL-I $\beta$, interleukin I $\beta$; NF- $\kappa B$, nuclear factor $\kappa B$; ROS, reactive oxygen species; SWCNT, single-walled carbon nanotube; S, SWCNT; TNF- $\alpha$, tumor necrosis factor $\alpha$; Vc, ascorbic acid. 
showed no purpose, demonstrating that the memory ability of the mice after SWCNT exposure was damaged. In OFT, the fact that the short total travel distance and routes were concentrated in the border area suggests that the higher two SWCNT exposure concentrations could decrease the locomotor activity of mice, while the increased defecation number reflected growth in anxiety. Therefore, to explore the reasons underlying these adverse effects, we investigated the possibility of damage to the internal brain structure.

Many studies indicate the critical role that the hippocampus plays in cognitive abilities. Based on pyramidal neuron morphology and its sensitivity to anoxia, the hippocampus can be divided into several regions, termed $\mathrm{CA}_{1}-\mathrm{CA}_{4}{ }^{33} \mathrm{As}$ reported, there is a high degree of correlation between the function of $\mathrm{CA}_{1}$ pyramidal cells and conditioned reflex; the loss of pyramidal neurons in the $\mathrm{CA}_{1}$ region may even be sufficient to cause amnesia. ${ }^{34}$ Recently, the hippocampus has attracted significant attention as a region related to mood disorders, with some studies demonstrating that structural changes in this region play an important role in depressive illnesses, the symptoms of which include anxiety and decreased locomotor activity. ${ }^{35}$ The histological observations of mouse brain sections demonstrated that after exposure to SWCNTs at certain concentrations, pyramidal neurons in the $\mathrm{CA}_{1}$ region were damaged, and Nissl substance loss (ie, chromatolysis) took place in pyramidal cells, suggesting that neurotransmitter synthesis was affected, followed by an influence on the signal transmission between neurons. The cell damage could also partly account for the cognitive deficits and decreased locomotor activity in the mice after SWCNT exposure.

The cellular metabolism of all aerobic organisms produces ROS, which can be deleted by antioxidant enzymes and some nonenzymatic defenses. The imbalance between production and elimination of ROS is referred to as oxidative stress. ${ }^{36}$ The latter is related to tissue damage and is closely associated with further damage, such as that to large molecules including DNA, proteins, and lipids. ${ }^{37,38}$ According to some researchers, nanoparticles entered into the central nervous system could activate microglial cells to produce a large number of free radicals. ${ }^{39}$ Because of its high oxygen consumption, high iron and lipid content, and low antioxidant defense activity, ${ }^{40}$ the central nervous system is highly sensitive to oxidative stress, and oxidative stress-mediated toxicity of CNTs in the lung, liver, and testes has been reported. ${ }^{18,41,42}$ It is thus reasonable to consider oxidative stress as at least one of the causes of mouse brain damage in our study. Long-term elevation of ROS can be associated with lipid peroxidation of unsaturated fatty acids in the plasma membrane, so that MDA also becomes a representative biomarker of oxidative stress. GSH is a ubiquitous tripeptide, which primarily functions by reaction with hydrogen peroxide, but also scavenges other ROS molecules to prevent oxidation. ${ }^{42}$ In our study, after SWCNT exposure, the significant dose-dependent increases in ROS and MDA and the decrease in GSH collectively suggest that after SWCNT exposure, oxidative stress was induced in mouse brains. We propose that oxidative stress could be the starting point for the main mechanism accounting for the toxicity of SWCNTs in mouse brains.

The effect of oxidative stress depends upon its degree; according to the hierarchical oxidative stress hypothesis, ${ }^{43}$ the lowest level of oxidative stress is associated with cytoprotective responses, eg, those using antioxidant and detoxification enzymes. If this level of protection fails, the oxidative stress will lead to proinflammatory effects. Further escalation will trigger disturbances in mitochondrial function, resulting in cellular apoptosis or necrosis. Initially, proinflammatory signaling cascades, including the NF- $\mathrm{\kappa B}$ cascade, are activated. $\mathrm{NF}-\kappa \mathrm{B}$, a redox-sensitive transcription factor, can convert oxidative stress signals into changes in gene expression associated with diverse cellular activities such as induced expression of TNF- $\alpha$ and IL- $1 \beta .{ }^{44,45}$ Apoptosis can be induced by mitochondrial perturbation and the release of apoptosis factors. Caspases have proteolytic activity that cleaves proteins at aspartic acid residues, and different caspases have different specificities involving the recognition of neighboring amino acids. Once caspases are initially activated, there appears to be an irreversible commitment towards cell death. ${ }^{46}$ Therefore, the activation of caspase- 3 plays a pivotal role in apoptosis mechanisms. The results of our study suggest that SWCNT-induced oxidative stress could induce inflammation in mouse brains. NF- $\kappa \mathrm{B}$ was accumulated and thus enhanced the release of proinflammatory mediators TNF- $\alpha$ and IL- $1 \beta$. In addition, the increased activation of caspase- 3 revealed that it was activated as a result of the high levels of oxidative stress after SWCNT exposure.

According to the results, at concentrations as high as 6.25 and $12.50 \mathrm{mg} / \mathrm{kg} /$ day, not only was there a high level of oxidative stress and the occurrence of inflammation and even apoptosis, but functional and pathological lesions in the mouse brains were also detected. However, at a dose of $3.125 \mathrm{mg} / \mathrm{kg} /$ day, SWCNTs could induce only ROS accumulation, while inflammation and apoptosis were not detected. Furthermore, at this dose, there were no behavioral changes detected (Figure 9). This provides an important clue for us that close attention should be paid to the dose of SWCNTs applied in the nervous system to ensure safe administration in related medical applications. For example, $3.125 \mathrm{mg} / \mathrm{kg} /$ day 


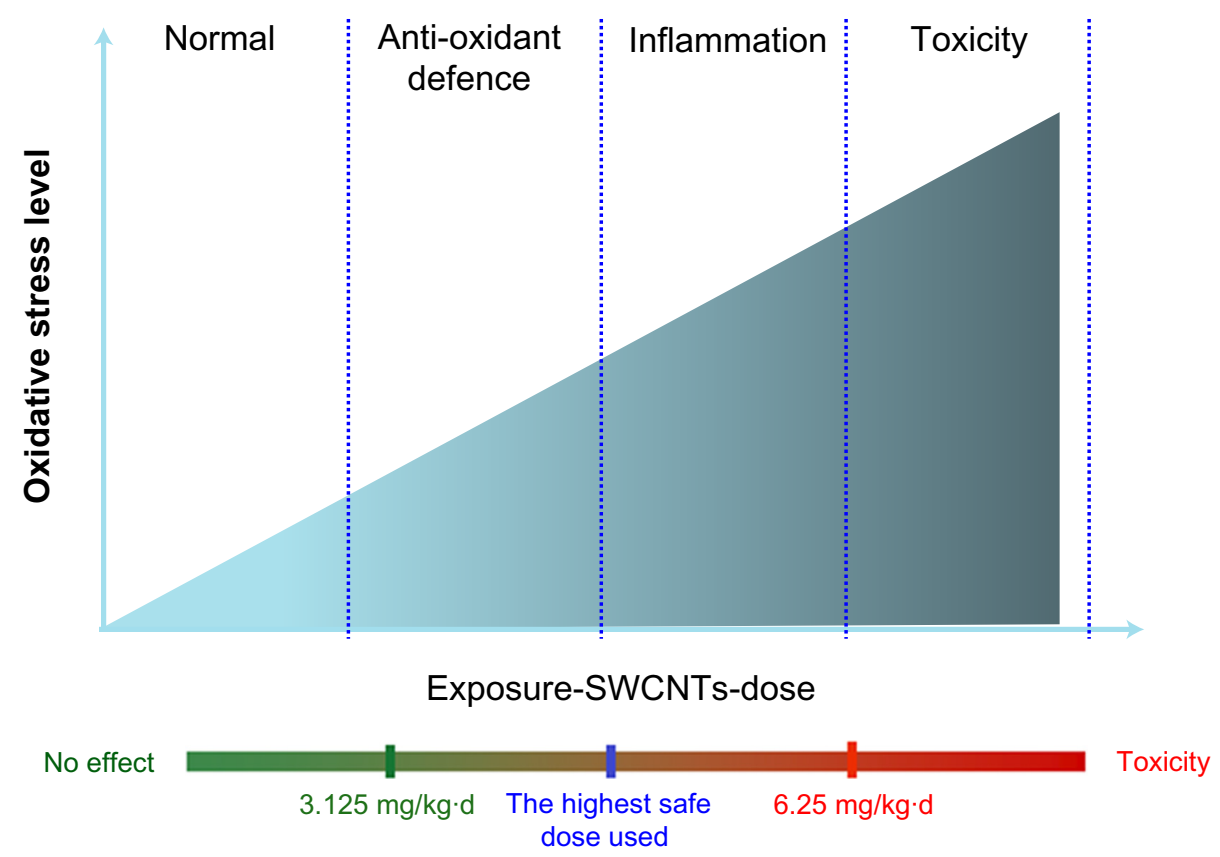

Figure 9 Relationship between the degree of damage and the level of oxidative stress.

Notes: At low concentration, damage is slight and brain function is not affected. However, as exposure concentration increases, inflammation and apoptosis occur in the brain, damage worsens, and brain function is affected.

Abbreviation: SWCNT, single-walled carbon nanotube.

of SWCNTs was found to be a relatively safe dose for mice in this study. According to some researchers, the toxicity of carbon nanotubes may significantly differ between diameter and length; for example, long-CNTs more easily induce inflammation than short-CNTs. ${ }^{47}$ So, considering the highly diverse structures and properties of SWCNTs, humans are exposed to SWCNTs in a variety of ways, and having a lower tolerance than mice, humans may be more easily susceptible to damage. Hence, the use of effective protective agents in the application of SWCNTs appears to be a more

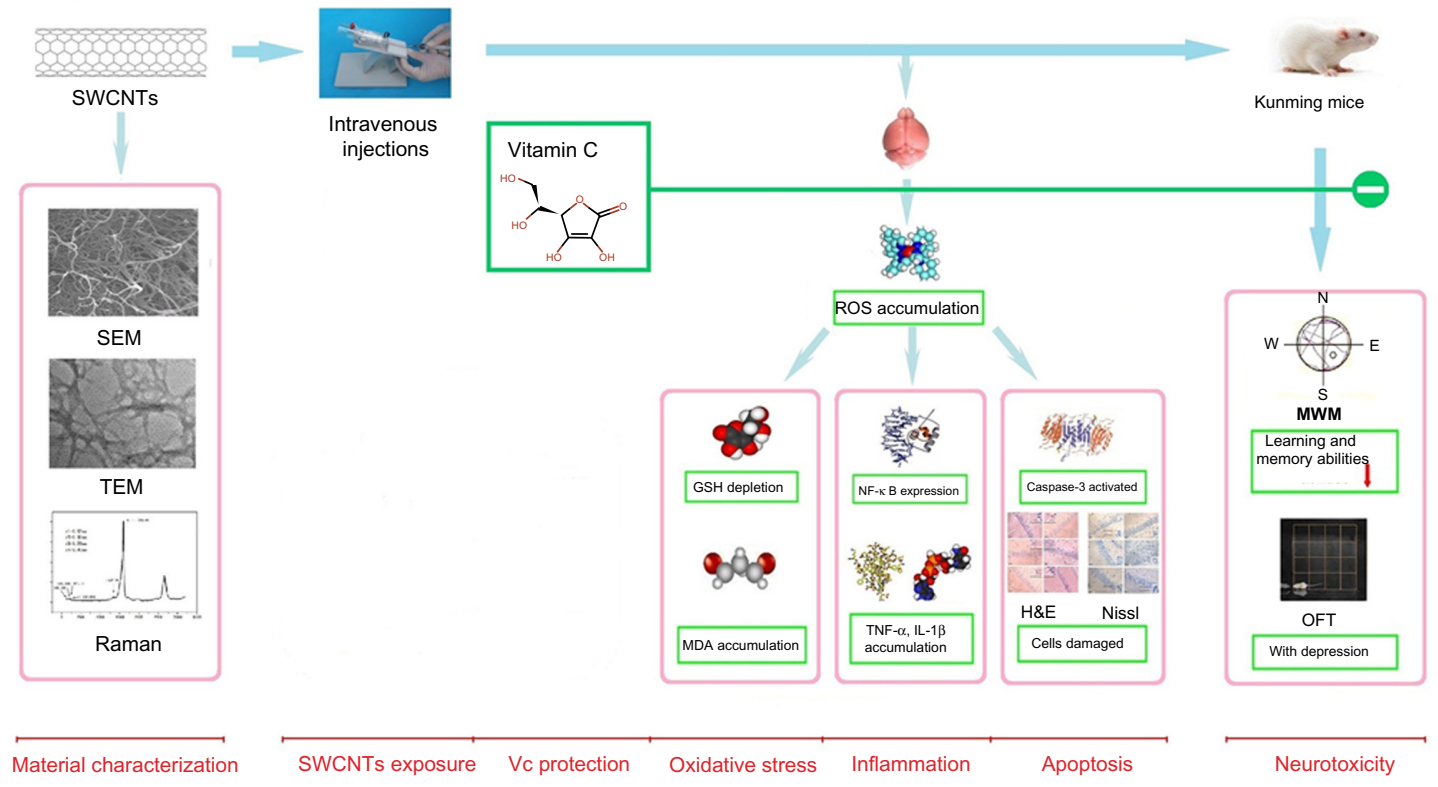

Figure 10 Potential mechanism of SWCNT-induced damage in mouse brains.

Notes: SWCNT-induced adverse effects in the mouse brain occurs through ROS generation and oxidative stress. Oxidative stress then induces inflammation and apoptosis in the brain, so that the functions of the brain are affected, while ascorbic acid protects cells through the down-regulation of oxidative stress.

Abbreviations: GSH, glutathione; H\&E, hematoxylin and eosin staining; IL-I $\beta$, interleukin I $\beta$; MDA, malondialdehyde; MWM, Morris water maze test; NF- $\kappa B$, nuclear factor $\mathrm{KB}$; OFT, open-field test; ROS, reactive oxygen species; SEM, scanning electron microscopy; SWCNT, single-walled carbon nanotube; TEM, transmission electron microscopy; TNF- $\alpha$, tumor necrosis factor $\alpha$; Vc, ascorbic acid. 
reliable approach to avoid associated damage to organisms. In addition, protective mechanisms should be explored.

Antioxidants, both endogenous and dietary, can be considered as a first line of defense against the generation of ROS. ${ }^{48}$ Ascorbic acid is a water-soluble vitamin with antioxidant properties that is readily absorbed by organisms. As the results show, administration of ascorbic acid significantly mitigated the damage to mice by SWCNTs, and the cognitive abilities of the mice were improved and the decreased locomotor activity of the mice attenuated. The levels of brain cell damage, oxidative stress, inflammation, and apoptosis were also reduced. Thus, oxidative stress might be the bestdeveloped paradigm to explain nanoparticle-induced toxicity. According to many studies from other groups, damage to the brain could be caused by the uptake of various nanoparticles by neuronal tissues, including not only nanometals or metal oxides, ${ }^{49-51}$ but also ambient nanoparticles. ${ }^{52,53}$ In these studies, oxidative stress was also found to be one of the most important mechanisms involved in such damage. A similar situation has been observed in the administration of graphitic nanomaterials, such as graphene, nano-C60, and ultrafine carbon black. ${ }^{54,55}$ Accordingly, it is highly possible that ascorbic acid may act as a protective agent against brain damage induced by other nanoparticles through down-regulation of the oxidative stress level.

\section{Conclusion}

To increase the safety of biomedical applications of SWCNTs to the nervous system in vivo, our study aimed to determine the effect of SWCNTs on mouse brains and to explore a suitable protective agent against damage. In conclusion, the results suggest that SWCNTs will induce in mice cognitive deficits, decreased locomotor activity, and damage to the brain via oxidative stress. Furthermore, ascorbic acid was found to protect cells from damage by down-regulating the level of oxidative stress (Figure 10). Generally, more attention should be paid to the concentration of SWCNTs and the simultaneous use of protective agents when SWCNTs are applied in the biomedical area. Further study on the protective effects of ascorbic acid against toxicity induced by other promising nanomaterials is urgently needed to ensure their safe administration.

\section{Acknowledgments}

This work was funded by the Exchange and Cooperation Program between Hong Kong and Mainland of Chinese Ministry of Education, the Chongqing Natural Science Foundation (No cstc2012jjA1137), the National Natural Science Foundation of China (No 21103059 and 51136002) and China Key Technologies R\&D Program (No 2012BAJ02B0301). All of the authors wish to thank Associate Professor Xiaomei Liao for providing the MWM devices and associated advice. We gratefully acknowledge Edanz Editing for editing the manuscript.

\section{Disclosure}

The authors report no conflicts of interest in this work.

\section{References}

1. Kostarelos K, Bianco A, Prato M. Promises, facts and challenges for carbon nanotubes in imaging and therapeutics. Nat Nanotechnol. 2009;4:627-633.

2. Yun YH, Dong Z, Shanov V, et al. Nanotube electrodes and biosensors. Nano Today. 2007;2:30-37.

3. Kam NWS, O'Connell M, Wisdom JA, et al. Carbon nanotubes as multifunctional biological transporter and near-infrared agents for selective cancer cell destruction. Proc Natl Acad Sci U S A. 2005;102: 11600-11605.

4. Liu A, Honma I, Zhou H. Simultaneous voltammetric detection of dopamine and uric acid at their physiological level in the presence of ascorbic acid using poly (acrylic acid)-multiwalled carbon-nanotube composite-covered glassy-carbon electrode. Biosens Bioelectron. 2007;23:74-80.

5. Nguyen-Vu TD, Chen H, Cassell A, et al. Vertically aligned carbon nanofiber arrays: an advance toward electrical-neural inferfaces. Small. 2006;2:89-94.

6. Sorkin R, Gabay T, Blinder P, et al. Compact self-wiring in cultured neuronal networks. J Neural Eng. 2006;3:95-101.

7. Chao TI, Xiang S, Lipstate JF, et al. Poly(methacrylic acid)-grafted carbon nanotube scaffolds enhance differentiation of hESCs into neuronal cells. Adv Mater. 2010;22:3542-3547.

8. Chao TI, Xiang S, Chen CS, et al. Carbon nanotubes promote neuron differentiation from human embryonic stem cells. Biochem Biophys Res Commun. 2009;384:426-430.

9. Yang ST, Guo W, Lin Y, et al. Biodistribution of pristine sing-walled carbon nanotubes in vivo. $J$ Phys Chem C. 2007;111:17761-17764.

10. Kateb B, Handel MV, Zhang L, et al. Internalization of MWCNTs by microglia: possible application in immunotherapy of brain tumors. Neuroimage. 2007;Suppl 37:9-17.

11. Al-Jamal KT, Gherardini L, Bardi G, et al. 2011. Functional motor recovery from brain ischemic insult by carbon nanotube-mediated siRNA silencing. Proc Natl Acad Sci U S A. 2011;108:10952-10957.

12. Singh R, Pantarotto D, Lacerda L, et al. Tissue biodistribution and blood clearance rates of intravenously administered carbon nanotubes radiotracers. Proc Natl Acad Sci U S A. 2006;103:3357-3362.

13. Manna SK, Sarkar S, Barr J, et al. Single-walled carbon nanotube induces oxidative stress and activates nuclear transcription factorkappa B in human keratinocytes. Nano Lett. 2005;5:1676-1684.

14. Shvedova AA, Kisin E, Murray AR, et al. Inhalation vs aspiration of single-walled carbon nanotubes in C57BL/6 mice: inflammation, fibrosis, oxidative stress and mutagenesis. Am J Physiol Lung Cell Mol Physiol. 2008;295:552-565.

15. Ravichandran P, Periyakaruppan A, Sadanandan B, et al. Induction of apoptosis in rat lung epithelial cells by multiwalled carbon nanotubes. J Biochem Mol Toxicol. 2009;23:333-344.

16. Warheit DB, Laurence BR, Reed KL, et al. Comparative pulmonary toxicity assessment of single-wall carbon nanotubes in rats. Toxicol Sci. 2004;77:117-125.

17. Li Z, Hulderman T, Salmen R, et al. Cardiovascular effects of pulmonary exposure to single-wall carbon nanotubes. Environ Health Perspect. 2007;115:277-382. 
18. Bai YH, Zhang Y, Zhang JP, et al. Repeated administrations of carbon nanotubes in male mice cause reversible testis damage without affecting fertility. Nat Nanotechnol. 2010;5:683-689.

19. Zhang YB, Ail SF, Dervishi E, et al. Cytotoxicity effects of grapheme and sing-wall carbon nanotubes in neural phaeochromocytoma-derived PC12 cells. ACS Nano. 2010;4:3181-3186.

20. Belyanskaya L, Weigel S, Hirsch C, et al. Effects of carbon nanotubes on primary neurons and glial cells. Neurotoxiclogy. 2009;30:702-711.

21. Coulter JA, Jain S, Butterworth KT, et al. Cell type-dependent uptake, localization, and cytotoxicity of $1.9 \mathrm{~nm}$ gold nanoparticles. Int $J$ Nanomedicine. 2012;7:2673-2685.

22. Oberdörster G, Maynard A, Donaldson K, et al. Principles for characterizing the potential human health effects from exposure to nanomaterials: elements of a screening strategy. Part Fibre Toxicol. 2005;2:8.

23. Wei QH, Zhang J, Sun XJ, et al. Brain toxicity of single-walled carbon nanotubes on mice. Acta Bioch Bioph Sin. 2010;42:25.

24. Kataoka T, Nishiyama Y, Yamato K, et al. Comparative study on the inhibitory effects of antioxidant vitamins and radon on carbon tetrachloride-induced hepatopathy. J Radiat Res. 2012;53:830-839.

25. Yoshida M, Watanabe C, Honda A, et al. Emergence of delayed behavioral effects in offspring mice exposed to low levels of mercury vapor during the lactation period. J Toxicol Sci. 2013;38:1-6.

26. Davis MM, Olausson P, Greenqard P, et al. Refulator of calmodulin signaling knockout mice display anxiety-like behavior and motivational deficits. Eur J Neurosci. 2012;35:300-308.

27. Han B, Guo J, Abrahaley T, et al. Adverse effect of nano-silicon dioxide on lung function of rats with or without ovalbumin immunization. PLoS One. 2011;6:e17236.

28. Ning N, Dang X, Bai C, et al. Panax notoginsenoside produces neuroprotective effects in rat model of acute spinal cord ischemiareperfusion injury. J Ethnopharmacol. 2012;139:504-512.

29. Lowry OH, Rosebrough NJ, Farr AL, et al. Protein measurement with the Folin phenol reagent. J Biol Chem. 1951;193:265-275.

30. Wu D, Lu J, Zhang Y, et al. Ursolic acid improves domoic acid-induced cognitive deficits in mice. Toxicol Appl Pharmacol. 2013;271:127-136.

31. Tandon V, Gupta RK. Effect of Vitex negundo on oxidative stress. Indian J Pharm. 2005;37:38-40.

32. Cha KE, Myung H. Cytotoxic effects of nanoparticles assessed in vitro and in vivo. J Microbiol Biotechnol. 2007;17:1573-1578.

33. Eichenbaum H. Hippocampus: cognitive processes and neural representations that underlie declarative memory. Neuron. 2004;44:109-120.

34. Zola-Morgan S, Squire LR, Amaral DG. Human amnesia and the medial temporal region: enduring memory impairment following a bilateral lesion limited to field $\mathrm{CA}_{1}$ of the hippocampus. J Neurosci. 1986;6: 2950-2967.

35. Campbell S, MacQueen G. The role of the hippocampus in the pathophysiology of major depression. J Psychiatry Neurosci. 2004;29: 417-426.

36. Yang Z, Zhang Y, Yang Y, et al. Pharmacological and toxicological target organelles and safe use of sing-walled carbon nanotubes as drug carriers in treating Alzheimer disease. Nanomedicine. 2010;6:427-441.

37. Das M, Babu K, Reddy NP, et al. Oxidative damage of plasma proteins and lipids in epidemic dropsy patients: Alterations in antioxidant status. Biochim Biophys Acta. 2005;1722:209-217.
38. Sidorczuk MG, Brzóska MM, Jurczuk M, et al. Oxidative damage to proteins and DNA in rats exposed to cadmium and/or ethanol. Chem Biol Interact. 2009;180:31-38.

39. Calderón-Garcidueñas L, Maronpot RR, Torres-Jardon R, et al. DNA damage in nasal and brain tissues of canines exposed to air pollutants is associated with evidence of chronic brain inflammation and neurodegeneration. Toxicol Pathol. 2003;31:524-538.

40. Halliwell B. Oxidative stress and neurodegeneration: where are we now? J Neurochem. 2006;97:1634-1658.

41. Warheit DB, Laurence BR, Reed KL, et al. Comparative pulmonary toxicity assessment of single-wall carbon nanotubes in rats. Toxicol Sci. 2004;77:117-125

42. Kermanizadeh A, Gaiser BK, Hutchison GR, et al. An in vitro liver model-assessing oxidative stress and genotoxicity following exposure of hepatocytes to a panel of engineered nanomaterials. Part Fibre Toxicol. 2012;9:28

43. Xiao GG, Wang MY, Li N, et al. Use of proteomics to demonstrate a hierarchical oxidative stress response to diesel exhaust particle chemicals in a macrophage cell line. J Biol Chem. 2003;278:50781-50790.

44. Brown DM, Donaldson K, Borm PJ, et al. Calcium and ROS-mediated activation of transcription factors and TNF-alpha cytokine gene expression in macrophages exposed to ultrafine particles. Am J Physiol Lung Cell Mol Physiol. 2004;286:L344-L353.

45. Shankar E, Vykhovanets EV, Vykhovanets OV, et al. High-fat diet activates pro-inflammatory response in the prostate through association of Stat-3 and NF-кB. Prostate. 2012;72:233-243.

46. Taylor RC, Cullen SP, Martin SJ, et al. Apoptosis: controlled demolition at the cellular level. Nat Rev Mol Cell Biol. 2008;9:231-241.

47. Murphy FA, Schinwald A, Poland CA, et al. The mechanism of pleural inflammation by long carbon nanotubes: interaction of long fibres with macrophages stimulates them to amplify pro-inflammatory responses in mesothelial cells. Part Fibre Toxicol. 2012;9:8.

48. Contestabile A. Oxidative stress in neurodegeneration: mechanisms and therapeutic perspective. Curr Top Med Chem. 2001;1:553-568.

49. Hussain SM, Javorina AK, Schrand AM, et al. The interaction of manganese nanoparticles with PC-12 cells induces dopamine depletion. Toxicol Sci. 2006;92:456-463.

50. Wang J, Zhou G, Chen C, et al. Acute toxicity and biodistribution of different sized titanium dioxide particles in mice after oral administration. Toxicol Lett. 2007;168:176-185.

51. Elder A, Gelein R, Silva V, et al. Translocation of inhaled ultrafine manganese oxide particles to central nervous system. Environ Health Perspect. 2006;114:1172-1178.

52. Calderón-Garcidueñas L, Azzarelli B, Acuna H, et al. Air pollution and brain damage. Toxicol Pathol. 2002;30:373-389.

53. Campbell A, Oldham M, Becaria A, et al. Particulate matter in polluted air may increase biomarkers of inflammation in mouse brain. Neurotoxicology. 2005;26:133-140.

54. Oberdörster E. Manufactured nanomaterials (fullerences, C60) induce oxidative stress in the brain of juvenile largemouth bass. Environ Health Perspect. 2004;112:1058-1062.

55. Tin-Tin-Win-Shwe, Yamamoto S, Ahmed S, et al. Brain cytokine and chemokine mRNA expression in mice induced by intranasal instillation with ultrafine carbon black. Toxicol Lett. 2006;163:153-160. 


\section{Supplementary materials}
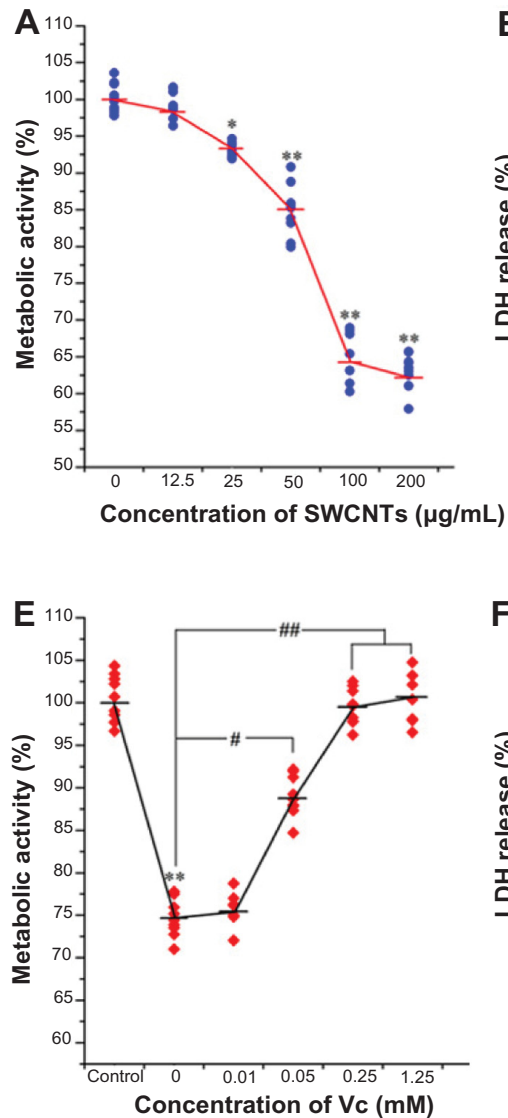
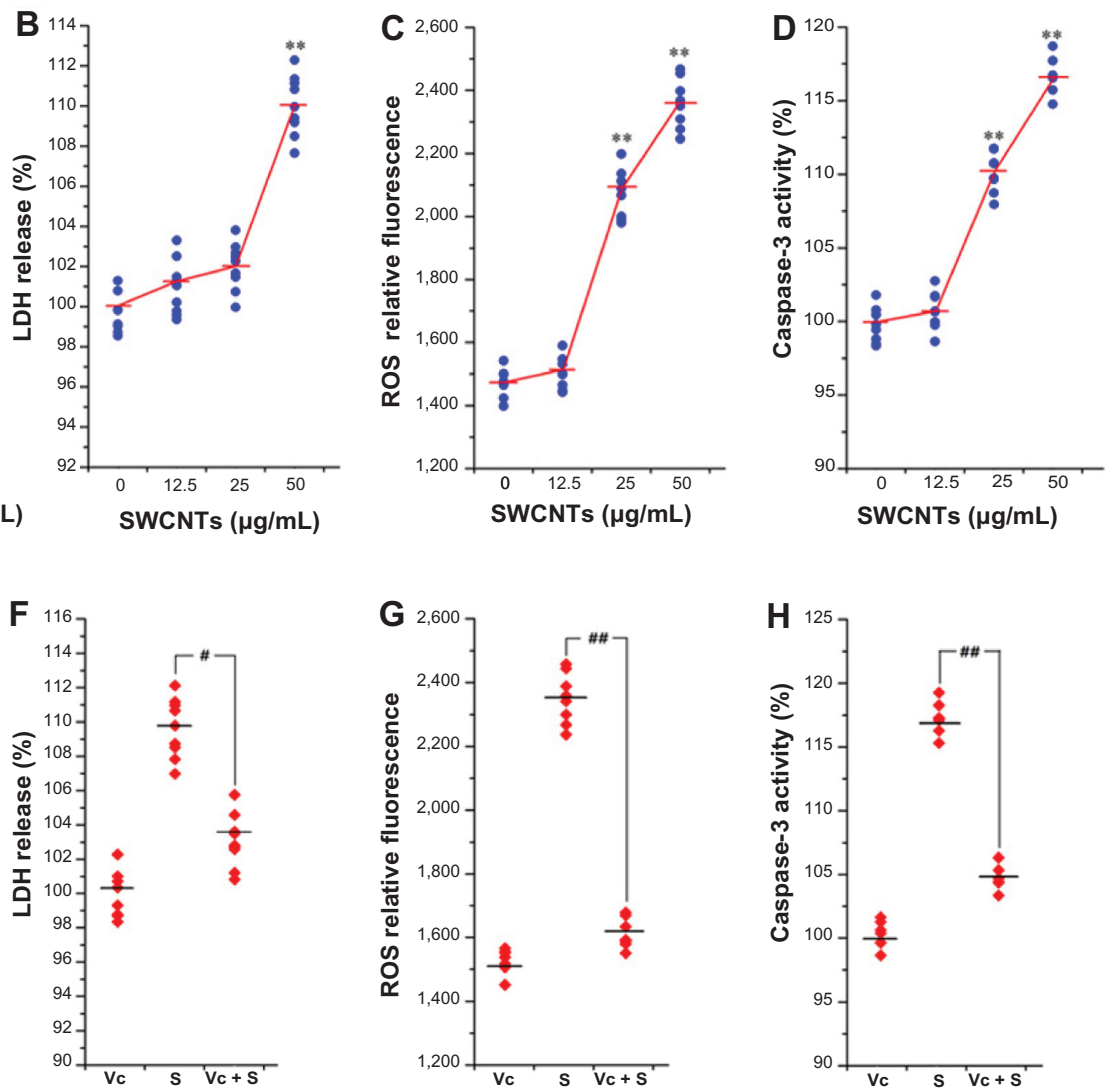

Figure SI Cytotoxicity characterizations of SWCNTs and protective effects of Vc in vitro.

Notes: (A) The metabolic activity of $\mathrm{N}_{2}$ a cells after SWCNT exposure was detected by the MTT assay. After 24 hours of exposure to SWCNTs, the metabolic activity of $\mathrm{N}_{2}$ a cells decreased in a dose-dependent manner. (B) LDH release was used to measure membrane damage, and there was an extremely significant LDH release at the highest concentration $(50 \mu \mathrm{g} / \mathrm{mL})$. (C) The generation of ROS was detected, and the 25 and $50 \mu \mathrm{g} / \mathrm{mL}$ groups both had extremely significant increases. (D) Caspase-3 activation was measured at 25 and $50 \mu \mathrm{g} / \mathrm{mL}$ SWCNTs, with exposure for 24 hours. Caspase-3 activation increased and indicated a caspase-3-mediated apoptotic pathway. (E) The metabolic activity of $\mathrm{N}_{2}$ a cells after $V_{c}$ protection. SWCNTs $50 \mu \mathrm{g} / \mathrm{mL}$ was used to detect the protective effect at different concentrations of $V_{c}(0,0.0 \mathrm{I}, 0.05,0.25$, and $1.25 \mathrm{mmol} / \mathrm{L}$ ). After 24 hours, the metabolic activity of $\mathrm{N}_{2}$ a was increased after $\mathrm{Vc}_{c}$ protection. $\mathrm{Vc}_{\mathrm{c}} 0.05 \mathrm{mmol} / \mathrm{L}$ had a significant protective effect on $\mathrm{N}_{2} \mathrm{a}$ cells, so $0.05 \mathrm{mmol} / \mathrm{L}$ Vc was used to protect the $\mathrm{N}_{2}$ a cells. (F) Vc down-regulated the LDH release level. Compared with the $50 \mathrm{~g} / \mathrm{mL}$ group, the block group decreased significantly. (G) The

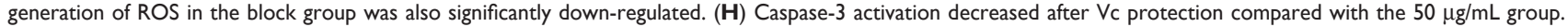
$* P<0.05 ; * * P<0.0$ I, compared with the control group $\left(0 \mu \mathrm{g} / \mathrm{mL}\right.$ SWCNTs); ${ }^{P}<0.05 ; \# P<0.0$ I, comparisons between the $50 \mu \mathrm{g} / \mathrm{mL}$ SWCNT group and the block group $(50 \mu \mathrm{g} / \mathrm{mL}$ SWCNTs $+0.05 \mathrm{mmol} / \mathrm{L} \mathrm{Vc})$.

Abbreviations: LDH, lactate dehydrogenase; MTT, 3-(4,5-Dimethylthiazol-2-yl)-2,5-diphenyltetrazolium bromide; $\mathrm{N}_{2}$ a, mouse neuroblastoma; ROS, reactive oxygen species; SWCNT, single-walled carbon nanotube; $\mathrm{Vc}$, ascorbic acid. 


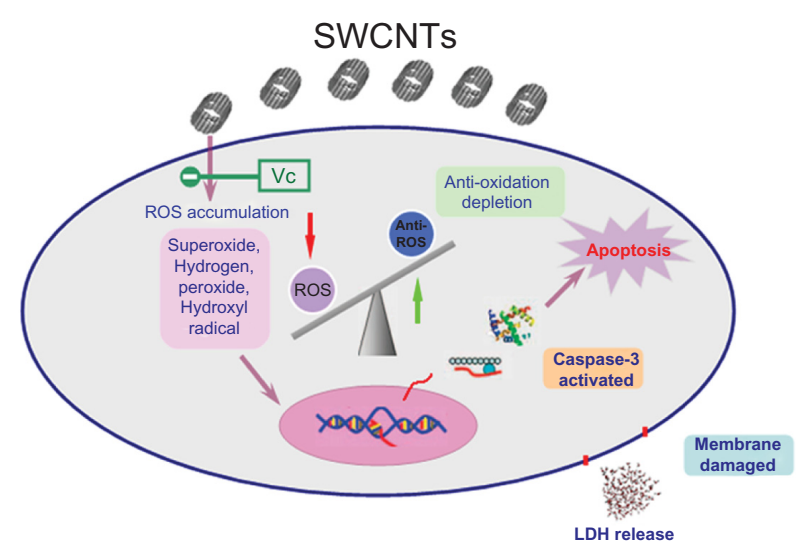

Figure S2 Potential mechanism of SWCNT-induced cytotoxicity on $\mathrm{N}_{2}$ a cells. After exposure to SWCNTs, $\mathrm{N}_{2}$ a cells are damaged, ROS is produced, and there is a high level of ROS-induced apoptosis and reduced metabolic activity of $\mathrm{N}_{2}$ a cells. $\mathrm{Vc}_{c}$ protects against the production of ROS and thus protects cells from damage. Abbreviations: $L D H$, lactate dehydrogenase; $\mathrm{N}_{2}$ a, mouse neuroblastoma; ROS, reactive oxygen species; SWCNT, single-walled carbon nanotube; $\mathrm{Vc}$, ascorbic acid.
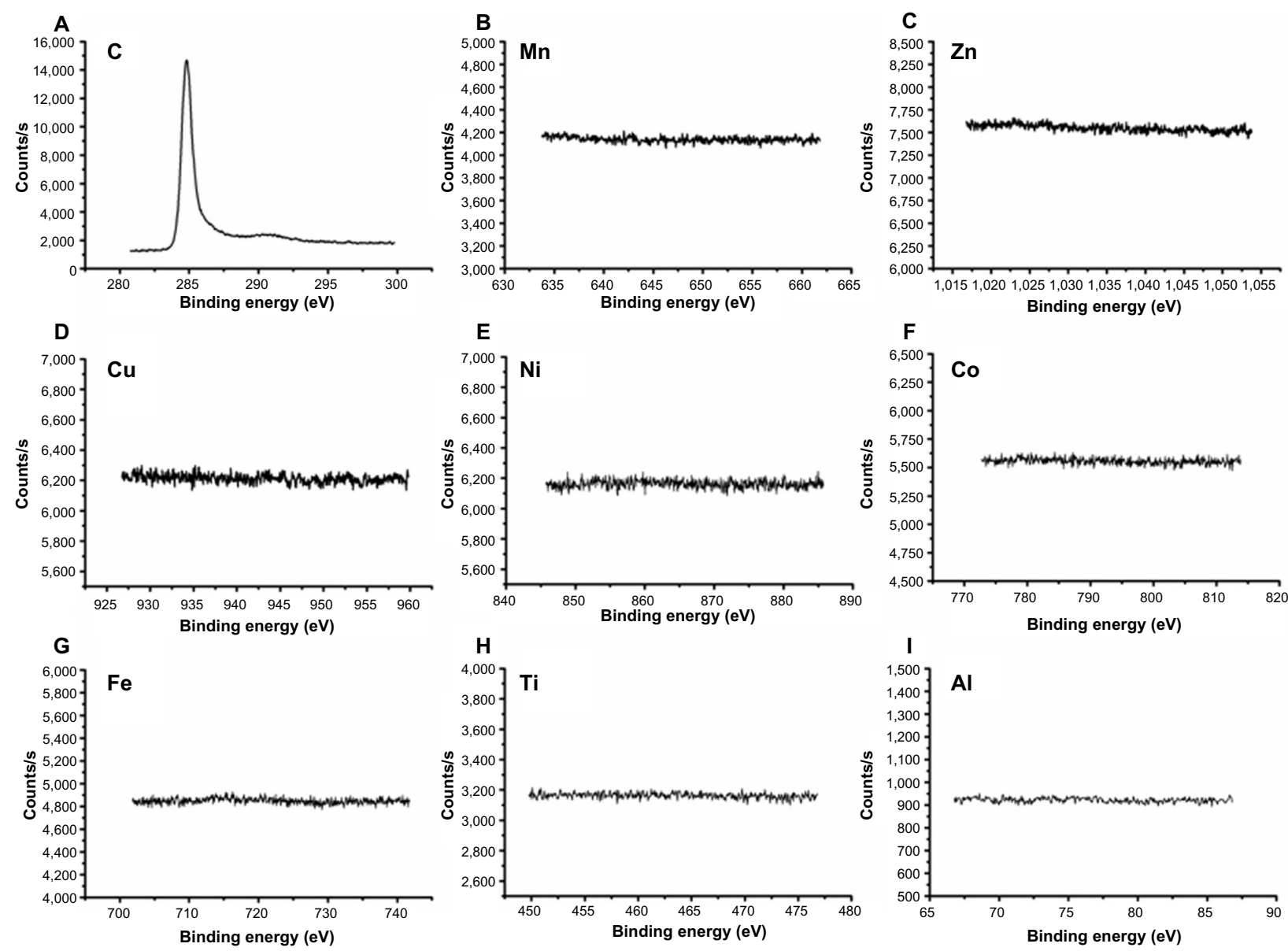

Figure S3 X-ray photoelectron spectra of single-walled carbon nanotubes: (A) C Is, (B) Mn 2p, (C) Zn 2p, (D) Cu 2p, (E) Ni 2p, (F) Co 2p, (G) Fe 2p, (H) Ti 2p, and (I) Al 2p.

Abbreviations: $\mathrm{C}$, carbon; $\mathrm{Mn}$, manganese; $\mathrm{Zn}$, zinc; $\mathrm{Cu}$, copper; $\mathrm{Ni}$, nickel; $\mathrm{Co}$, cobalt; Fe, iron; Ti, titanium; Al, aluminum; Counts/s, counts per second. 


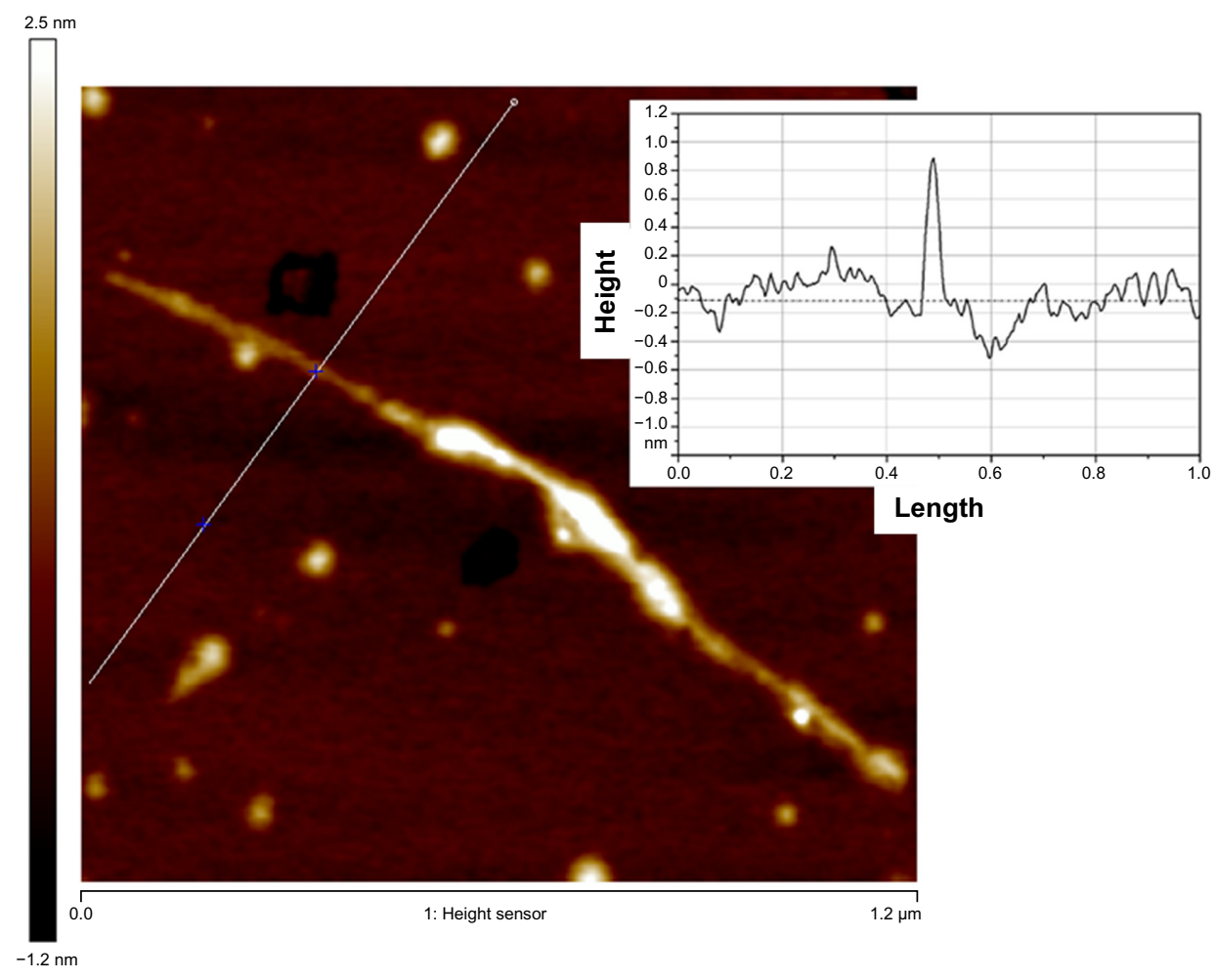

Figure S4 Atomic force microscopy image of single-walled carbon nanotubes. Note: The inset section curve shows the diameter of the carbon nanotubes.
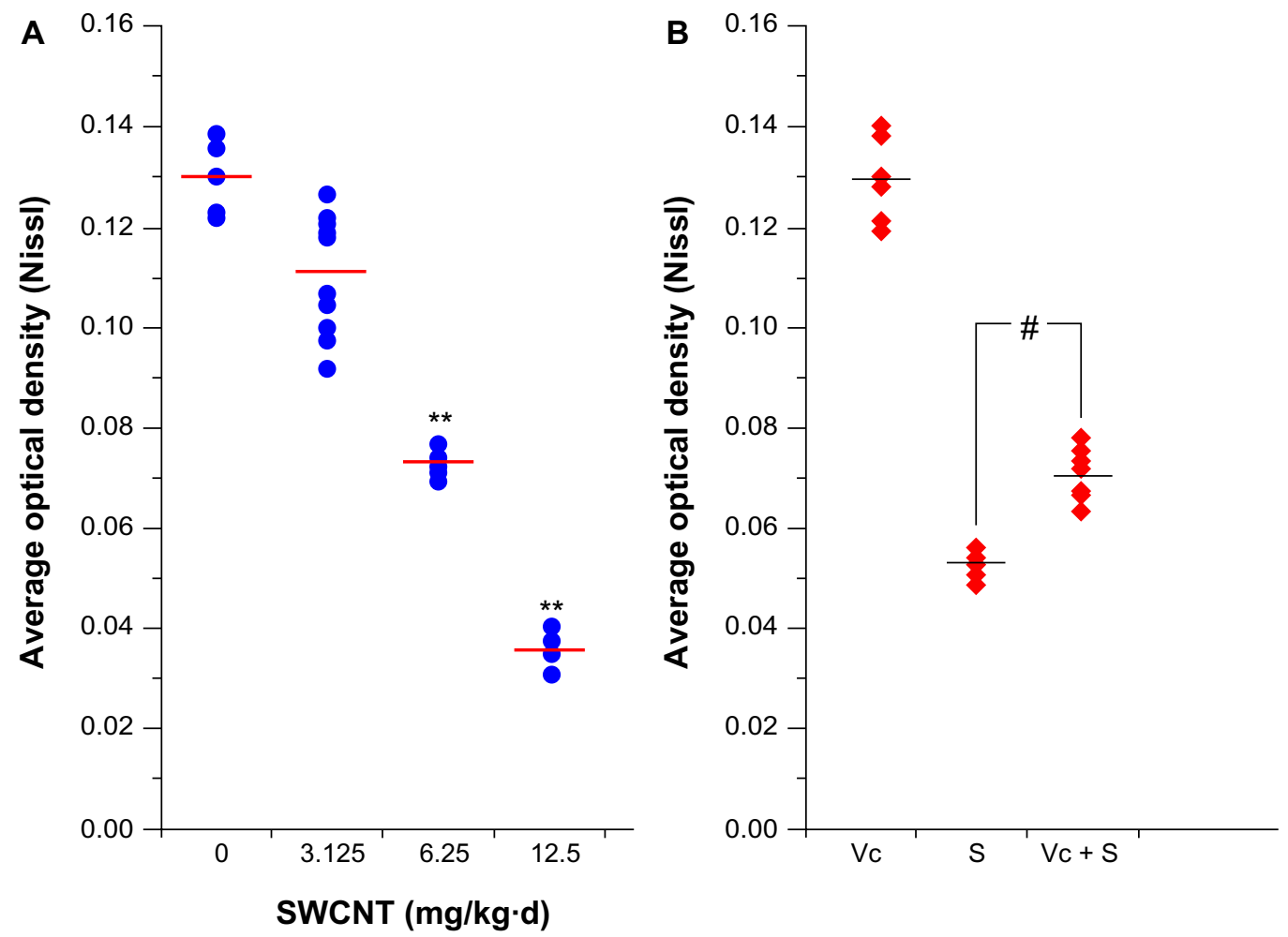

Figure S5 The average optical density of Nissl staining.

Notes: ${ }^{* * P}<0.01$, compared with the control group $\left(0 \mathrm{mg} / \mathrm{kg} /\right.$ day SWCNTs); ${ }^{\# P}<0.05$, comparisons between the $6.25 \mathrm{mg} / \mathrm{kg} /$ day $\mathrm{SWCNTs}$ group and the block group $(6.25$ $\mathrm{mg} / \mathrm{kg} /$ day SWCNTs + $100 \mathrm{mg} / \mathrm{kg} /$ day ascorbic acid).

Abbreviations: SWCNT, single-walled carbon nanotube; S, SWCNT; Vc, ascorbic acid. 
International Journal of Nanomedicine

Dovepress

\section{Publish your work in this journal}

The International Journal of Nanomedicine is an international, peerreviewed journal focusing on the application of nanotechnology in diagnostics, therapeutics, and drug delivery systems throughou the biomedical field. This journal is indexed on PubMed Central, MedLine, CAS, SciSearch ${ }^{\circledR}$, Current Contents ${ }^{\circledR} /$ Clinical Medicine,
Journal Citation Reports/Science Edition, EMBase, Scopus and the Elsevier Bibliographic databases. The manuscript management system is completely online and includes a very quick and fair peer-review system, which is all easy to use. Visit http://www.dovepress.com/ testimonials.php to read real quotes from published authors.

Submit your manuscript here: http://www.dovepress.com/international-journal-of-nanomedicine-journal 